\title{
REDUCING SHORT CIRCUIT LEVELS BY USING SYSTEM SPLITTING STRATEGIES
}

\author{
(Assist. Prof. Dr. Inaam I. ALI (Supervisor)), \\ Electrical Engineering Department, University of Technology, Baghdad,Iraq. \\ E-mail:In2006aam@yahoo.com. \\ Mohanad Sh. Tarad AL-AASAM (Researcher), \\ Electrical Engineering Department, University of Technology, Baghdad,Iraq. \\ General Company of Electric Energy Transportation for Middle Euphrates Region, Ministry of \\ Electricity \\ E-mail:tr_sh_mo2007@yahoo.com.
}

\begin{abstract}
Preliminary studies on Iraqi power system show a significant increase in the short circuit level at some of the grid substations and some power stations. This increasing results from the growth of the power generation and transmission systems in size and complexity. Islanding or splitting is dividing the power system into several islands inorder to reduce short circuit levels and avoiding blackouts. The main islanding problem is determining the location of proper splitting points and load balance and satisfaction of transmission capacity constraints for each islands.
\end{abstract}

This paper mainly introduces new proposed splitting strategies of large-scale power systems by using (PSS TME version 30.3 PACKAGE PROGRAME), such that, make reinterconnection of $400 \mathrm{KV}$ super high voltage substation based on three-phase load flow to be minimum flow at splitting point and infeed fault current details method to control short circuit levels in Iraq power system without islanding the power system into isolated islands. Controlled islanding or splitting scheme is frequently considered as the final solution to avoid blackouts of power system.

Simulation IEEE-25 bus and Iraqi power system used as the test systems for this method. Furthermore, simulation results show significant effectiveness on reducing short circuit levels with same time give stable splitting islands with same frequency for preventing the system blackouts.

Keywords: Short circuit current, Controlled Islanding, New Splitting strategies. Station Busbar of Highest Short Circuit Level (SBHSCL).

\section{INTRODUCTION}

Fault currents cause unacceptable thermal stresses and electrodynamic forces apply to the equipment's, increased step and touch voltages and personnel safety problems appear. Increased occurrences of faults decrease the lifetime power system components while also reduce the overall stability and reliability of the power system. The short circuit current is increasing usually because of arbitrary generation increasing and dummy complicated development of transmission systems in small land region. 


\section{AL-QADISIYAH JOURNAL FOR ENGINEERING SCIENCES}

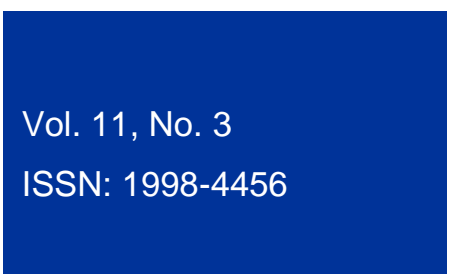

If the short circuit levels exceed the maximum designed short-circuit ratings of the switchgear, therefore, widespread power blackouts may occur. Furthermore, fault level is a measure of network robustness [1-4].

Detection of the fault current within the first cycle (less than 16 milliseconds for $60 \mathrm{~Hz}$ and 20 milliseconds for $50 \mathrm{~Hz}$ ) and reduction to a desired percentage in the next few cycles. During large disturbances subjected the power systems tend to cascading outages and transiently unstable if using uncontrolled system separation [5].

After several disturbances take place in the power grid, the overall system operates closer to its stability margin. Intentional islanding can effectively interrupt a sequence of cascading outages and prevents large area blockouts. It is proven that intelligent separation of power system into islands at the primary stage of cascade outages can reduce or even eliminates the risk of major blackouts. Intentional islanding, also known as controlled islanding, which is dividing the power system into isolated smaller islands in order to slightly degrade the detrimental impacts of the large disturbance which contain the impact of the disturbance could prevent. [6-9]. The main problems of control islanding are slow coherency and determines islands considering graph search methods such as ordered binary decision diagrams (OBDD) [10]. The slow coherency is the machines swinging together are said to be coherent with regard to the slow modes when a disturbance occurs, the oscillation of generator angles in an area is much faster than that between other areas, in other words, the generators machines belong to the same slow coherency group. After the intraarea oscillations decay, only inter-area oscillation exists and generators within the same area move together. The slow-coherence generator groupings are largely independent of fault location and to a lesser extent operating point and dependent on machine properties [11-12]. The ordered binary decision diagrams (OBDD) is a based method contain three static constraints are set and an optimum cutset under the three constraints, neither an effective algorithm for large systems nor any dynamic simulation on large systems. The proposed method simplifies the original power system using an effective graph theory based algorithm. Finally, it uses power-flow results to determine if any of the strategies satisfy inequality constraints. The major drawback of OBDD searching methods is that the simplification of the original power system may result in losing superior solutions [4,13-14]. In the recent years, several researchers proposed controlled islanding based on graph clustering algorithms. Neglecting generator behavior may split power system into instable islands $[7,15]$. In practice, network splitting or islanding is much more common and less expensive approach to fault level reduction. But, choices of separation for any grid into islands loss of $24 \%$ load. Separating the grid during the fault have $100 \%$ risk $[16,17]$.

\section{THE PROPSED SPLITTING STRATEGIES}

Controlled splitting of a power system is an efficient corrective measure for limiting system blackouts after a large disturbance has occurred. It limits the occurrence and consequences of blackouts by splitting the minimized number of stations busbars of the main power system. Controlled islanding has the same main offline or online procedure in implementation by power system operators.

i. Offline studies: may be implemented daily or yearly and involved the following items:

- Check and determine the location and number of the optimization points for islanding or splitting.

- Insure about having approved synchro phasors devices siting near generators.

- Perform validation or choices for a control islanding or splitting strategy table.

ii. Online monitoring: - may be implemented every second and involved the following items:

a. Identify most vulnerable grid interface by checking the dominant oscillation mode and shape.

b. Predict the timing of power system instability on the interface.

iii. Real-Time control: - may be implemented every milliseconds and performed a control strategy that matching the load flow and short circuit levels analysis and power system connection conditions [17].

The proposed splitting strategies can depend on the procedure for reducing short circuit level.

The procedure for the proposed splitting strategies is simple, low steps and maintain the supplying loads before splitting. The proposed splitting strategies. 

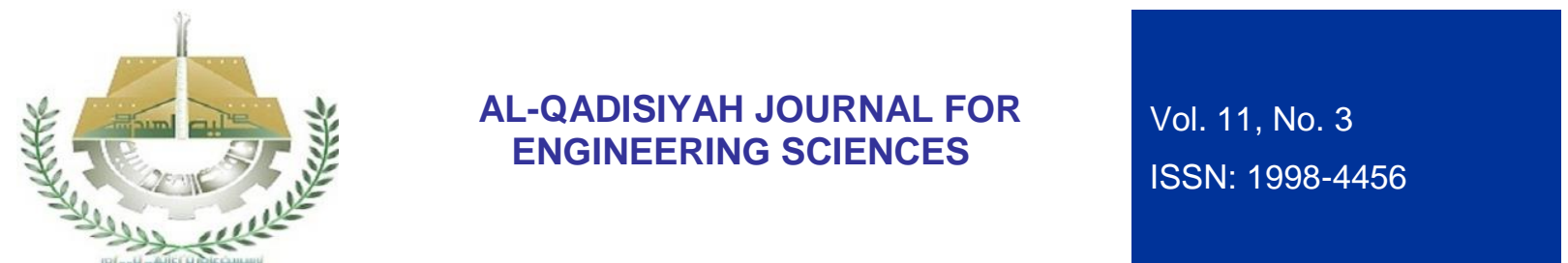

\section{APPROPRIATE LOCATION OF SPLITTING:}

The main problem of Iraqi grid is some of the substations and power stations busbars in the 400kV Iraqi grid have restricted short circuit levels for their equipment's. Interrupting and mean life of the high voltage circuit breakers depend on their maximum values of short circuit current during fault and each circuit breaker for different levels of voltages have maximum manufacturer specification design short circuit current, known that the cost circuit breakers may vary rabidly for different values of short circuit current at the same voltage level. Faults have short circuit current higher than the maximum value of manufacturer short circuit current of the circuit breaker may damage it and then cascading blackouts may occur. In controlled islanding, the determining of islanding locations depend on which tie lines may be switched off. Deviation of the supplied load and the generation power, number of substations in each island, value of the new different frequencies of each island and the amount of reducing short circuit levels compared to the overall old system specifications before islanding for each choice give the efficiency of each choice. In the proposed new splitting method, the power system remains at the same frequency and same generation power but the deviation of supplied loads depend on the location of splitting and number of splitting in the power system which depend on load flow and details short circuit feeding current analysis at the station busbar splitting location. Choosing the optimal choice depend on that choice have minimum number of splitting, minimum amount or no deviation of supplied loads and generation power and have the highest reducing of short circuit levels. The appropriate splitting location will be at the highest voltage level stations if the short circuit levels at that side level and the largest amount of fault feeding current come from the sources directly. In Iraqi power system grid the highest voltage level and the main problem at $400 \mathrm{kV}$, then can choose the $400 \mathrm{kV}$ stations for the location of splitting, so that are beneficiaries from that station design or type. In Iraq power system has breaker and half $400 \mathrm{kV}$ stations type. Connection and reconnection for a $400 \mathrm{kV}$ side switchyard of the power station as an example power station has six diameters, six transmission lines and six step up power transformers with six generator units. In Figures (1 and 2) sequentially would explain the method where Figure (1) illustrated normal operation of $400 \mathrm{kV}$ side switchyard of the power station such that all transmission lines (L1, L2, L3, L4, L5 and L6) and generator units (G1, G2, ,G3, G4, G5 and G6) connected with (BB1 and BB2). Figure (2) illustrate the splitting connection choice by controlling the operation diameters circuit breakers such that (the transmission lines (L1, L3, L5, G1, G2 and G5 feed BB1) and (L2, L4, L6, G3, G4 and G6 feed BB2) known that all six transmission lines (L1, L2, L3, L4, L5 and L6) connected with the same power system .

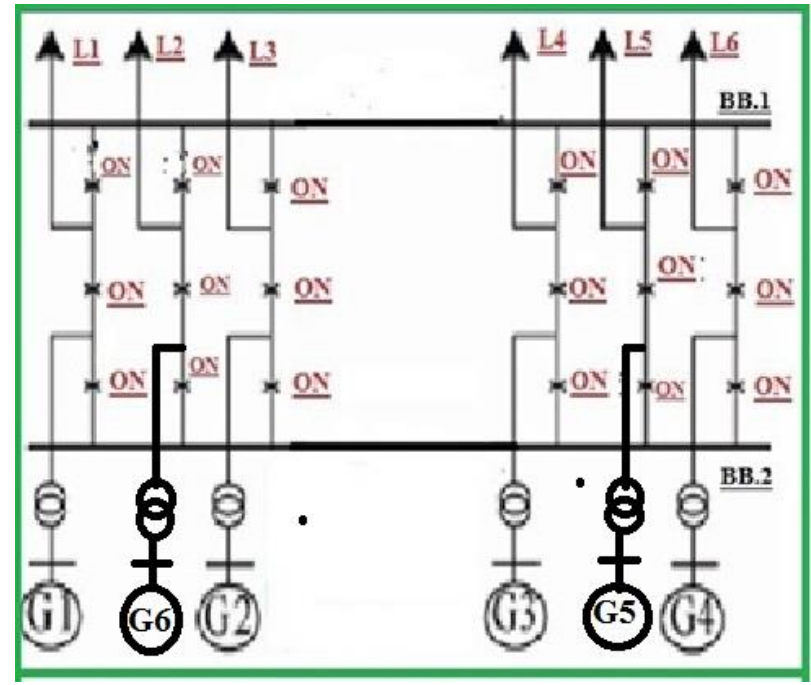

Figure (1): Single line diagram of $400 \mathrm{KV}$ side network for power station.

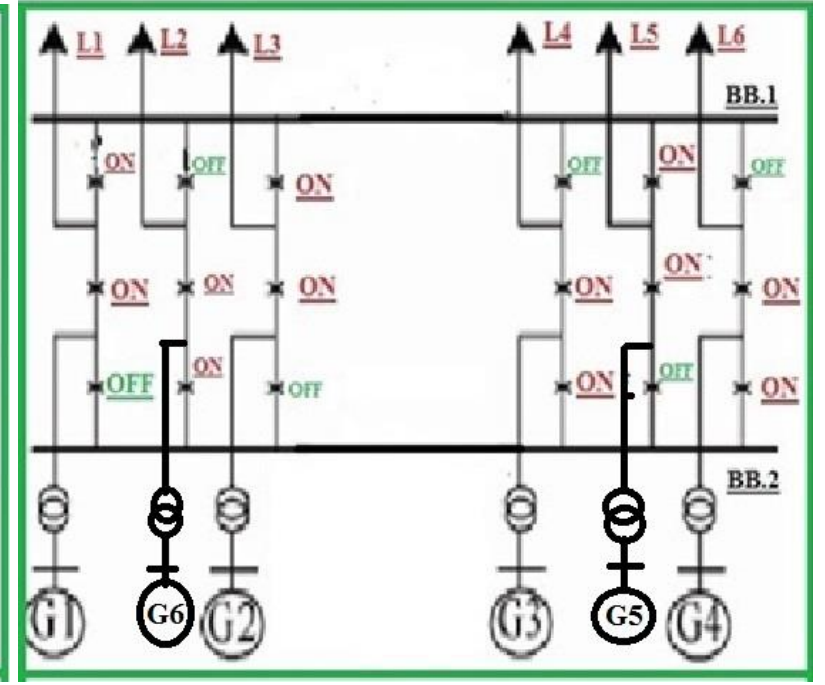

Figure 2: Single line diagram of $400 \mathrm{KV}$ side network for power station after splitting. 


\section{AL-QADISIYAH JOURNAL FOR ENGINEERING SCIENCES}

Vol. 11 , No. 3

ISSN: $1998-4456$

\section{THE ALGORITHEM OF THE PROPOSED SPLITTING STRATIEGES}

The details procedure of the proposed method is given and illustrated in figure (3) as follows: .

1. Start checking load flow of the programmable system using the flat condition with Newton Raphson solution method technique.

2. Checking the detail short circuit Levels of the system busbars as a case study, and identify the Station Busbar of Highest Short Circuit Level (SBHSCL).

3. Make a table about the fault feeding currents for each busbar during the fault show the flow diagram with load flow of the (SBHSCL) and determine the splitting choices may apply on the connection of the (SBHSCL) for one or more splitting strategies.

4. Checking the load flow and short circuit test for each choice.

5. Make a table for all choices mention above.

6. Represent all points for all choices values of the table done in step 5 above.

7. Choose the optimal choice which has the minimum times of splitting and the lowest values of the short circuit levels for (SBHSCL) and other substation in the system.

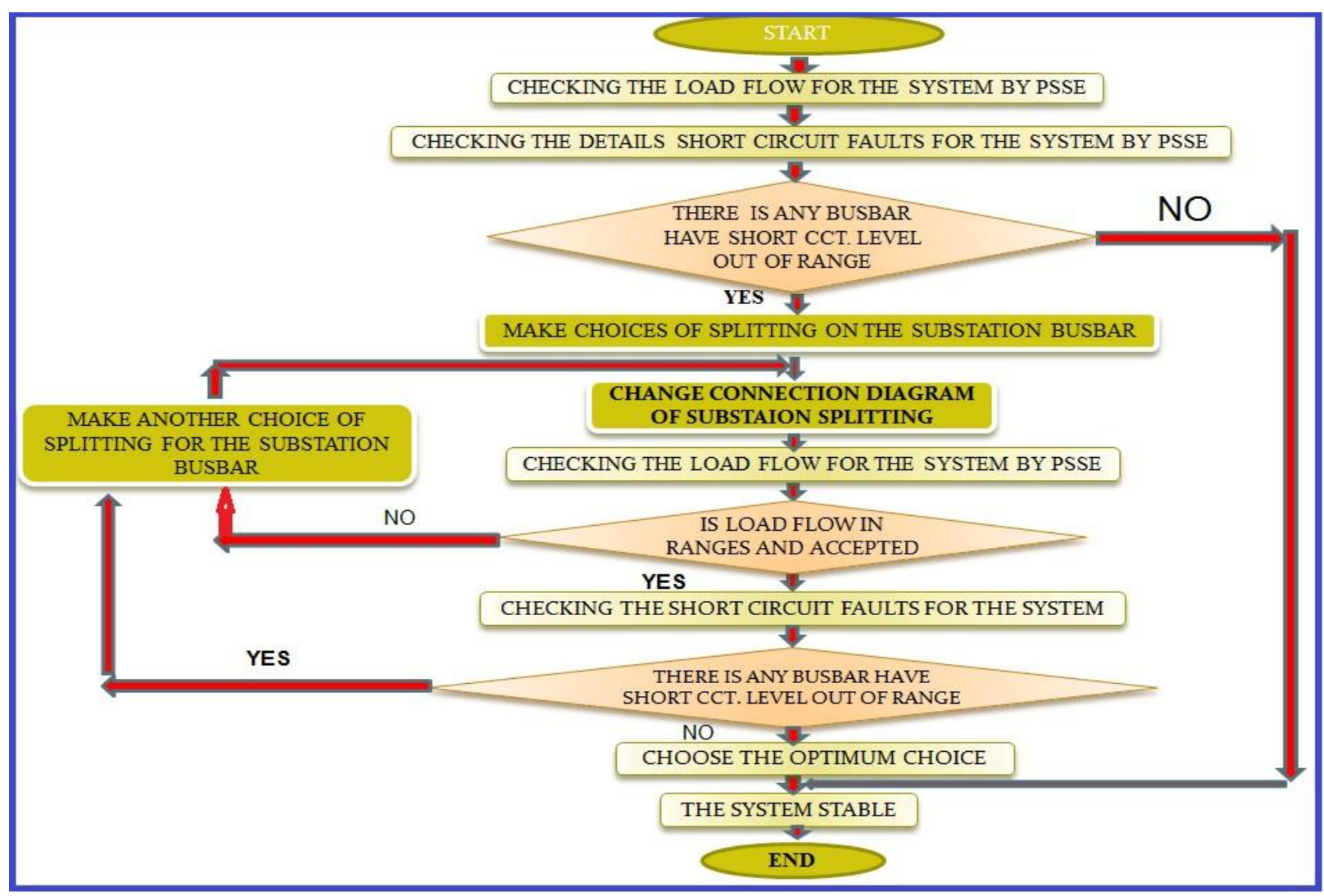

Figure (3): -Algorithm of proposed new splitting strategies

\section{ASSUMPTION AND SIMPLIFICATIONS:}

It is assumed that the system is balanced in presentation of system data and considered only one phase of the three-phase system. The impedances of the network are made up of balanced impedances. The generators have different impedance to the flow of positive, negative and zero sequence currents, a general assumption are made as follows:

- Equal voltage magnitude and in phase for positive sequence pre-fault voltage of all generated voltages.

- Identical positive and negative sequence networks.

- Except at fault points the networks are balanced.

- Negligible value for all line charging susceptance, etc. (shunt admittance). 


\section{AL-QADISIYAH JOURNAL FOR ENGINEERING SCIENCES}

Vol. 11 , No. 3

ISSN: $1998-4456$

\section{CASE STUDY}

\section{1 (STANDARD TEST SYSTEM):}

Simulation IEEE 25-bus network in Figure (4) will be taken as a test system for this method, where proper splitting strategies can be given quickly. Further analyses indicate that this method is useful and effective for larger-scale power systems.

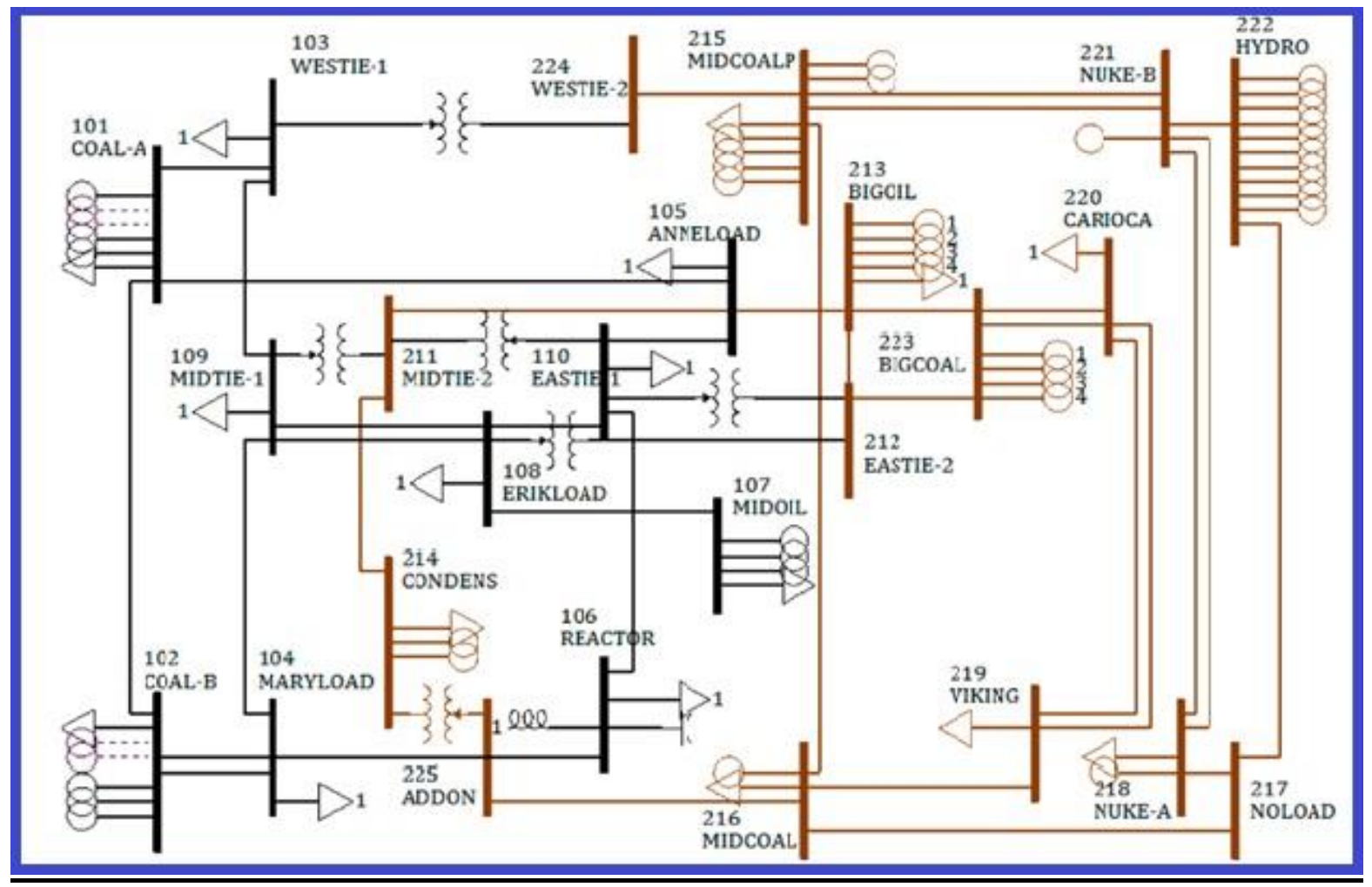

Figure (4): - single line diagram of IEEE 25-bus [18]

\subsection{PRACTICAL SYSTEM}

The practical system is the Iraq grid system information for (8-1-2018) and making analysis using (PSS ${ }^{\mathrm{TM}}$ E version 30.3 PACKAGE PROGRAME).

\section{SIMULATION AND RESULTS}

\subsection{CASE 1: - FOR TEST SYSTEM}

Implementing the procedure of the proposed method in section (4) as follows:

1. Start checking the load flow of the programmable system using the flat condition for Newton Raphson programmable load flow technique.

2. At the same time get a table about the fault feeding currents for each busbar during the fault as illustrated in tables (1and 2).

3. Check the load flow of the SBHSCL and determine the splitting choices may apply on the connection of the SBHSCL for one or more splitting strategies. 


\section{AL-QADISIYAH JOURNAL FOR ENGINEERING SCIENCES}

Vol. 11 , No. 3

ISSN: $1998-4456$
Table 1: - Infeed details current at 211 bus fault

\begin{tabular}{|c|c|c|c|}
\hline \multicolumn{2}{|c|}{ AT BUS 211 MIDTIE-2 } & \multicolumn{2}{|c|}{$\begin{array}{c}\text { THREE PHASE } \\
\text { FAULT }\end{array}$} \\
\hline Bus station & VOLTAGE KV & $\mathrm{RE}(\mathrm{I}+)$ & $\mathrm{IM}(\mathrm{I}+)$ \\
\hline 109 [MIDTIE-1] & 138.00 & 1.7229 & -12.9896 \\
\hline 110 [EASTIE-1] & 138.00 & 1.6613 & -12.697 \\
\hline 213 [BIGOIL] & 230.00 & 1.3549 & -14.2559 \\
\hline $\begin{array}{c}214 \\
\text { [CONDENS] }\end{array}$ & 230.00 & 1.132 & -13.1707 \\
\hline \multicolumn{2}{|c|}{ TOTAL FAULT CURRENT (P.U.) } & 5.8712 & -53.1132 \\
\hline
\end{tabular}

Table 2 :- Infeed details current at 212 bus faut

\begin{tabular}{|c|c|c|c|}
\hline & \multirow{2}{*}{$\begin{array}{c}\text { VOLTAGE } \\
\text { KV }\end{array}$} & \multicolumn{2}{|c|}{$\begin{array}{c}\text { THREE PHASE } \\
\text { FAULT }\end{array}$} \\
\cline { 1 - 2 } \cline { 4 - 4 } Bus station & & RE(I+) & IM(I+) \\
\hline 109 [MIDTIE-1] & 138 & 1.7586 & -13.7602 \\
\hline 110 [EASTIE-1] & 138 & 1.6918 & -13.4505 \\
\hline 213 [BIGOIL] & 230 & 1.3532 & -14.3192 \\
\hline 223 [BIGCOAL] & 230 & 0.9559 & -8.7467 \\
\hline \multicolumn{2}{|c|}{ TOTAL FAULT CURRENT (PU) } & 5.7595 & -50.2766 \\
\hline
\end{tabular}

4. Check load flow of the SBHSCL and determine the splitting choices may apply on the connection of the SBHSCL for one or more splitting strategies as shown figures (5 and 9) for (211 and 212) busbars sequentially. The way of determining choices depend on making the flow in splitting points at minimum values and which lines feeding the faults with large values divide between sections of splitting busbars. One splitting choices had two choices succeed in the load flow test the details of choices illustrated as follows:

One splitting at 211 MIDTIE-2 choice 1 (split 1): The (211 MIDTIE-2) busbar in figure (5) supply two transmission lines with the (213 and 214) stations and two power transformer, which divide electrically into two sections busbars (211 and 2119) shown in figure (6 and 7) sequentially. The procedure of choice is depending on load flow analysis such that the power values to be minimum available at splitting point before splitting as in Figure (8) and is taken in mind the values of infeed fault current in table (1) such that the transmission lines with busbars (213 and 214) must distribute on busbars (211 and 2119) by this procedure, then have several choices, after check the load flow for each choice may take the successful choice or choices, where, in this case the details of successful choice illustrated in Figures (6 and 7) for (211 and 2119) sequentially, such that (211 busbar) supply one transmission line with (213 BIGOL) and power transformer, furthermore, (2119) busbar supply transmission line with (214 CONDENS) and power transformer.

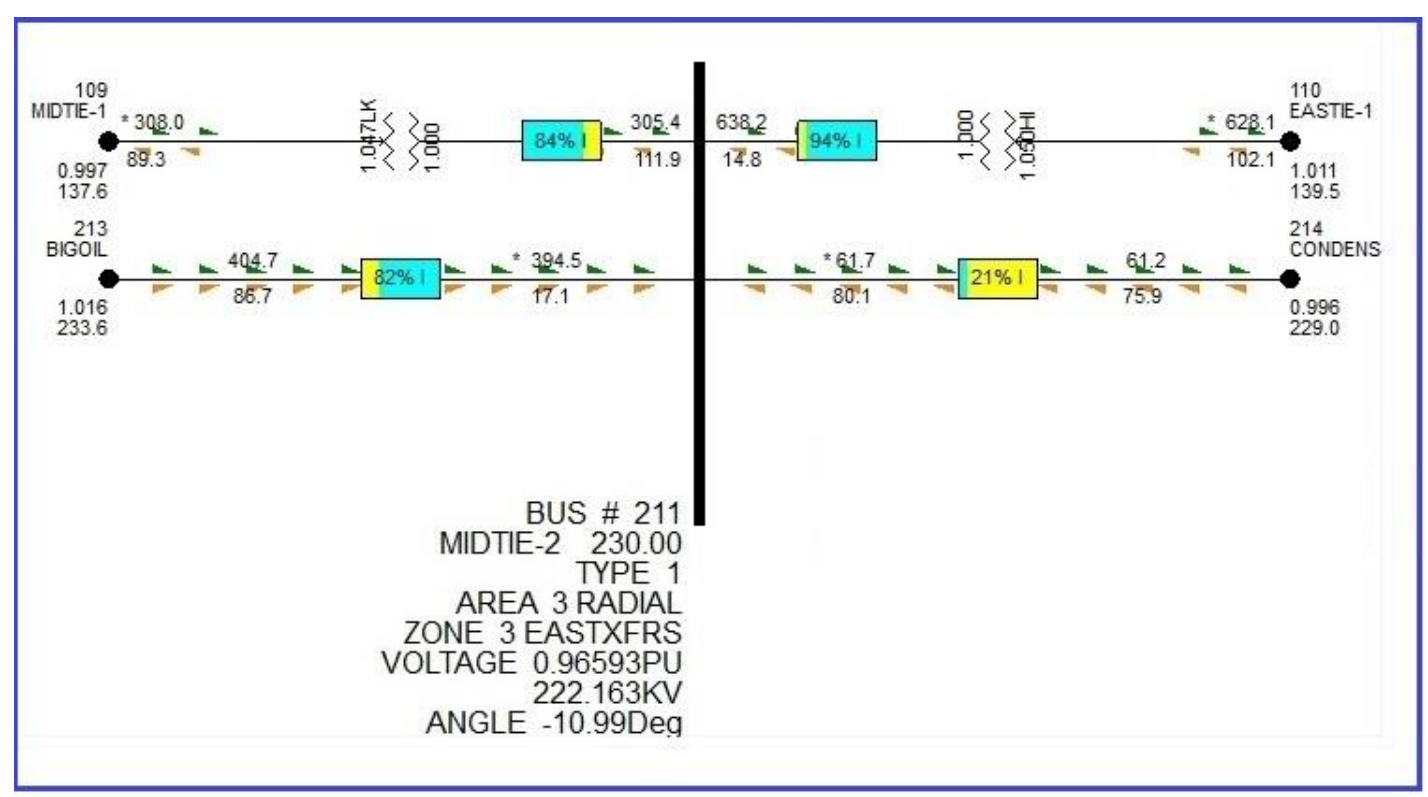

Figure 5: Single line diagram of bus \#211 MIDTIE-2 normal case. 


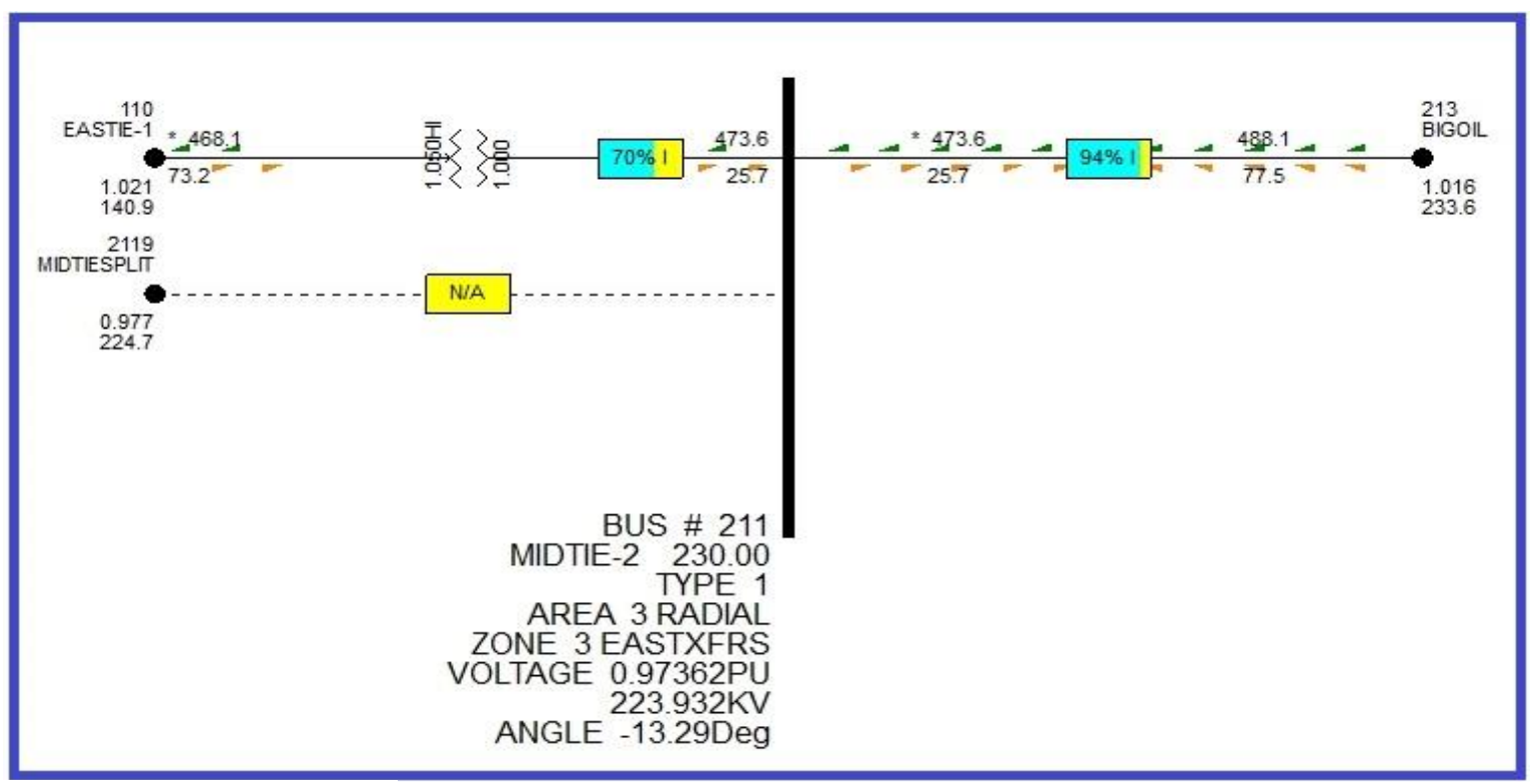

Figure 6: Single line diagram of bus \#211 MIDTIE-2 after splitting.

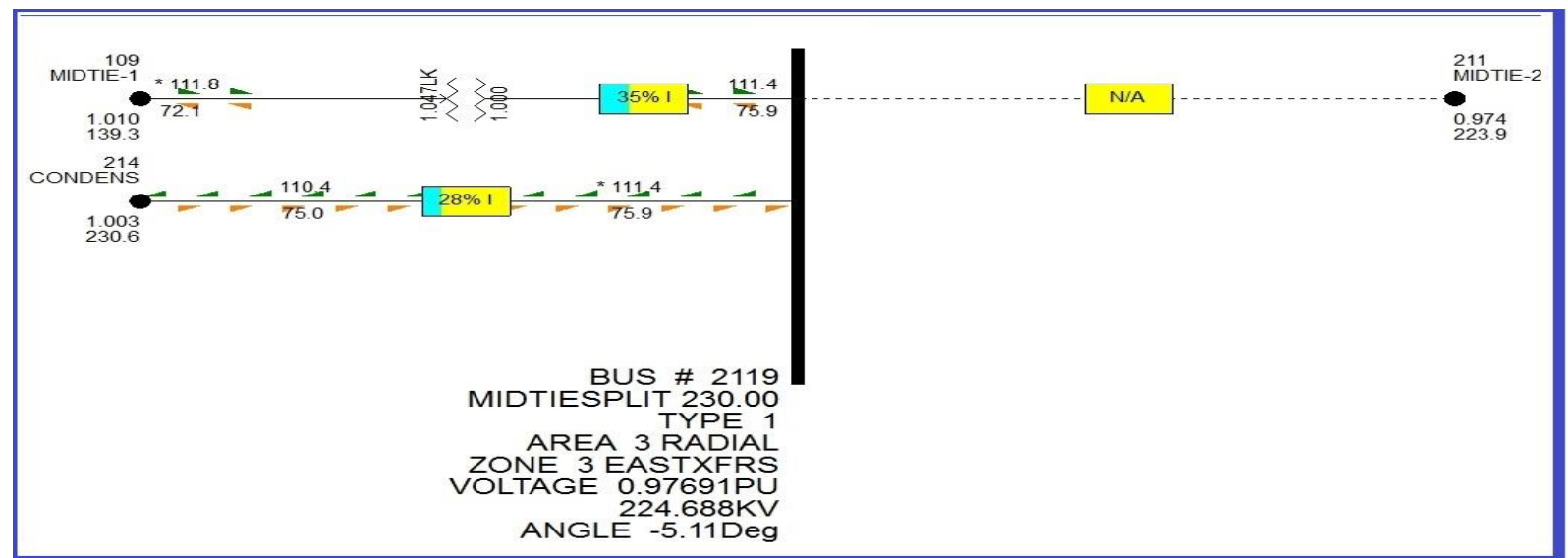

Figure 7: Single line diagram of bus \#2119 MIDTIE-2 after splitting.

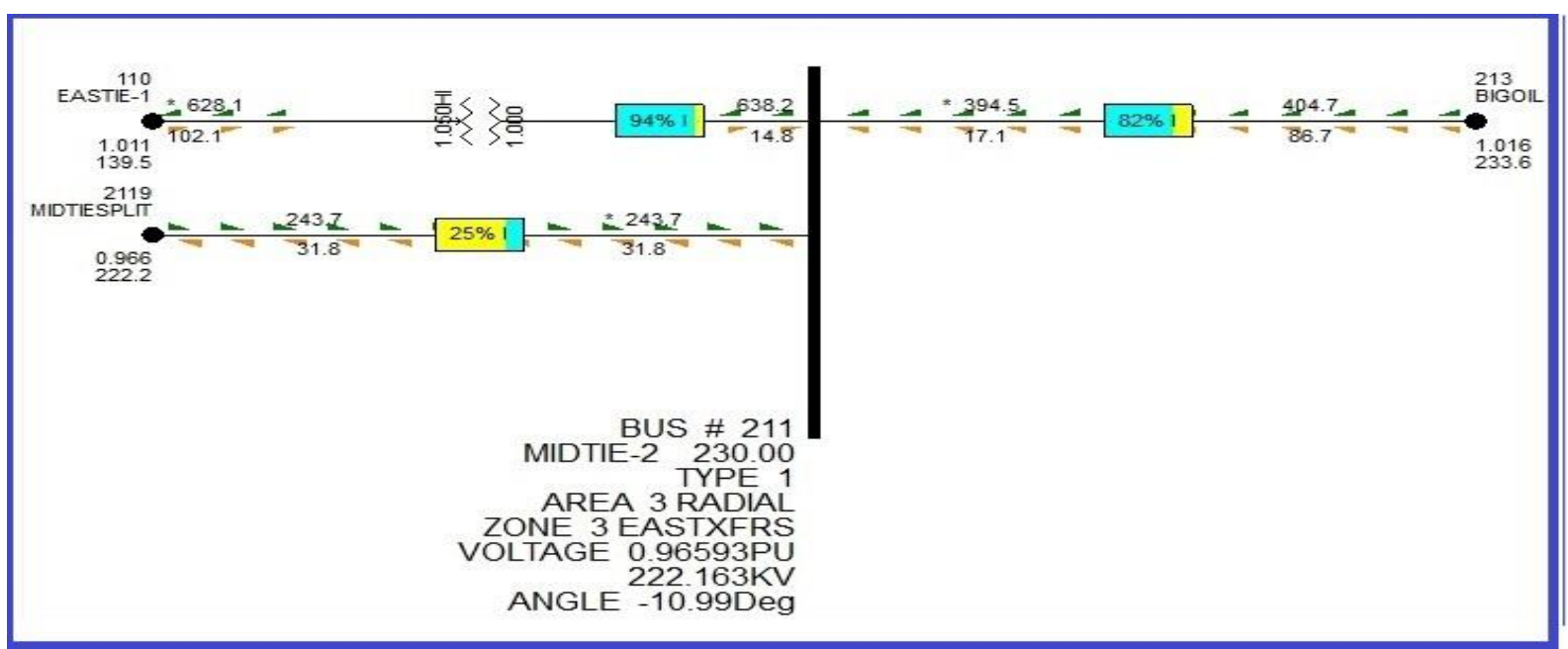

Figure 8: Single line diagram for Load Flow of bus \#211 MIDTIE-2 before splitting. 
AL-QADISIYAH JOURNAL FOR ENGINEERING SCIENCES
Vol. 11 , No. 3

ISSN: $1998-4456$

One splitting in BUS \#212 EASTIE-2 choice 2: The (212 EASTIE-2) busbar in Figure (9) supplied two transmission lines with the (213 and 223) stations and two power transformers, which divided electrically into two sections busbars(211 and 2119) shown in Figure (10 and 11) sequentially, the procedure of choice is depending on load flow analysis, such that the power values to be at minimum at splitting point before splitting as shown in Figure (12) and the values of infeed fault power in table (2) of the transmission lines with busbars (213 and 223) must give opinion of distributing transmission lines on busbars (212 and 2129) by this procedure, then had several choices, after check the successful choices in load flow analysis for each choice may take the successful choices, where, in this case the details of successful choice illustrated in Figures (11 and 12), such that (212 busbar) supplied one transmission lines with (213 busbar) and one power transformer, furthermore, (2129) busbar supplied one transmission line with (214 busbar) and one power transformer.

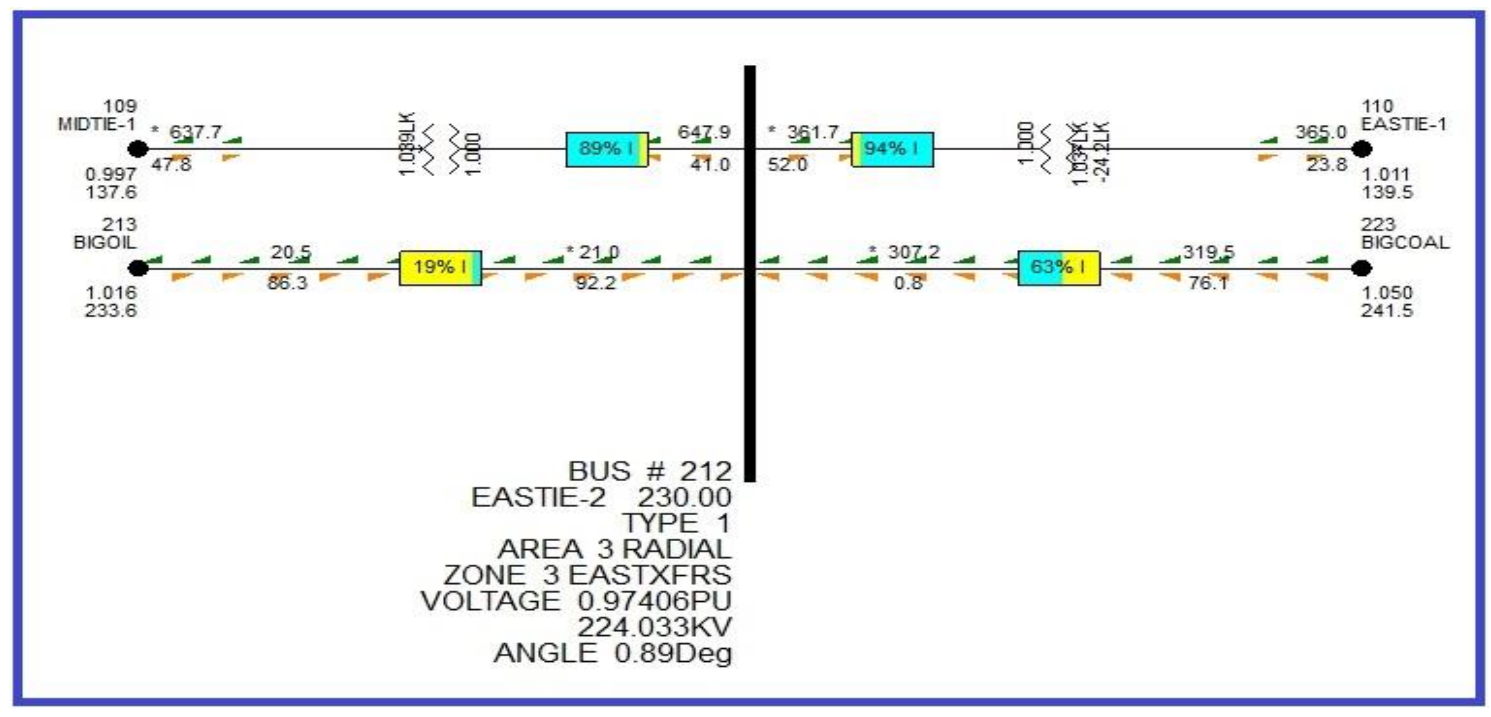

Figure 9: Single Line Diagram for Load Flow of BUS \#212 EASTIE-2

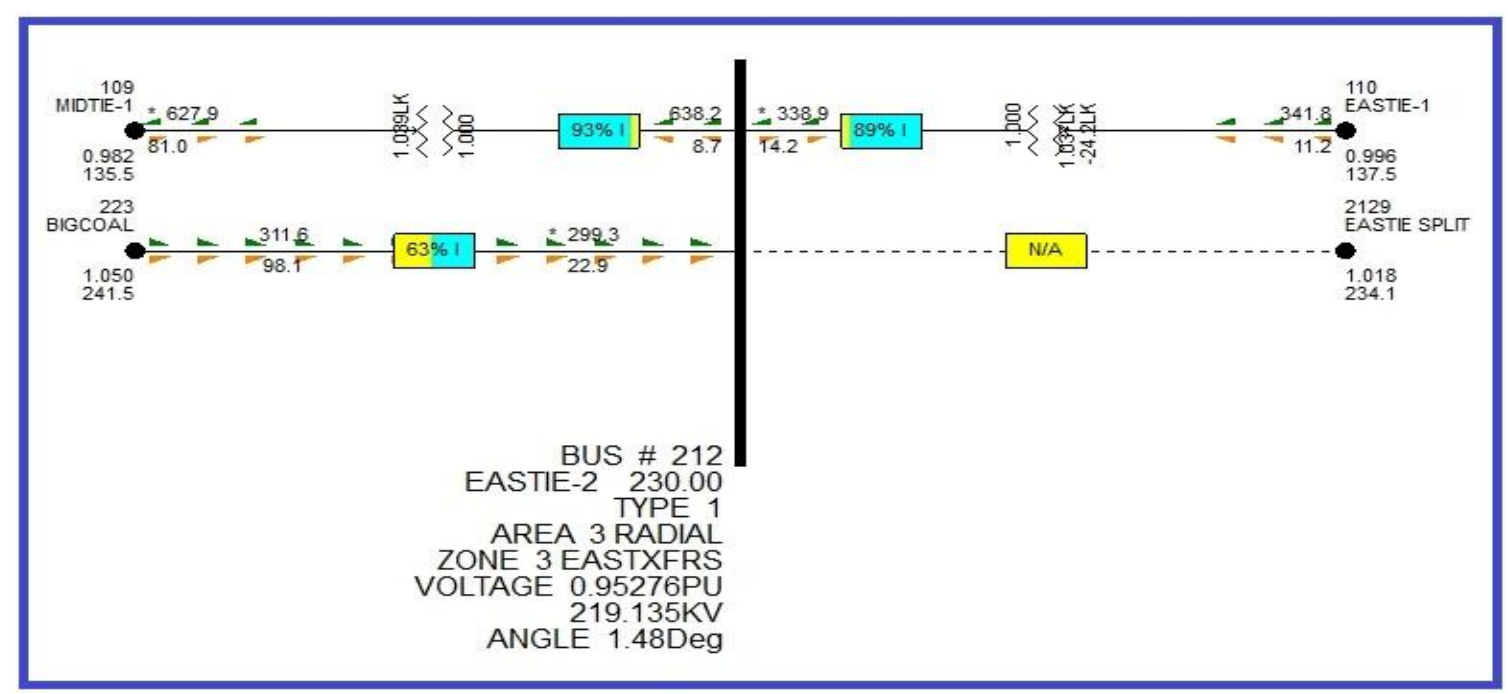

Figure 10: Single line diagram for Load Flow of bus \#212 MIDTIE-2 after splitting. 


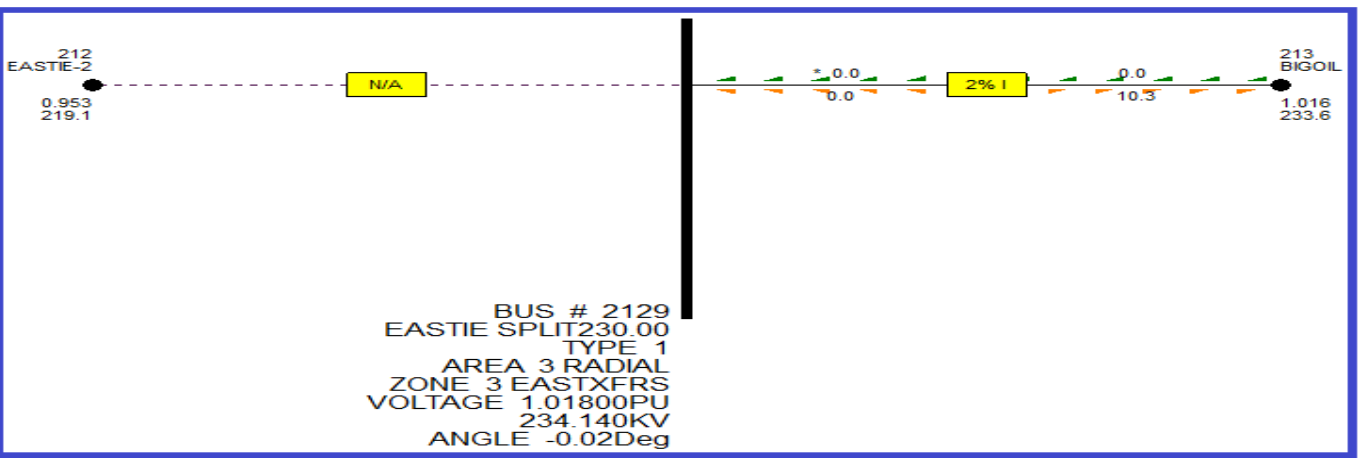

Figure 11: Single line diagram for Load Flow of bus \#2129 MIDTIE-2 after splitting.

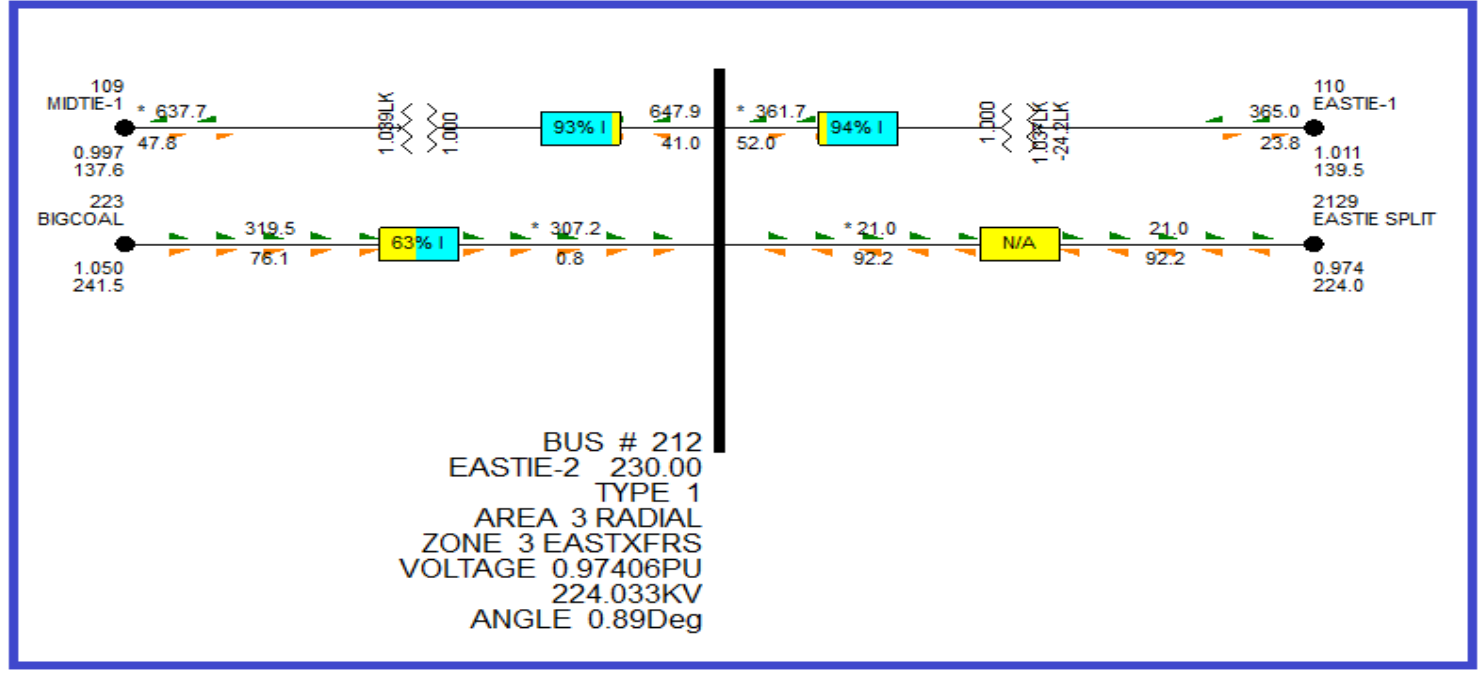

Figure 12: Single line diagram for Load Flow of bus \#211 MIDTIE-2 before splitting.

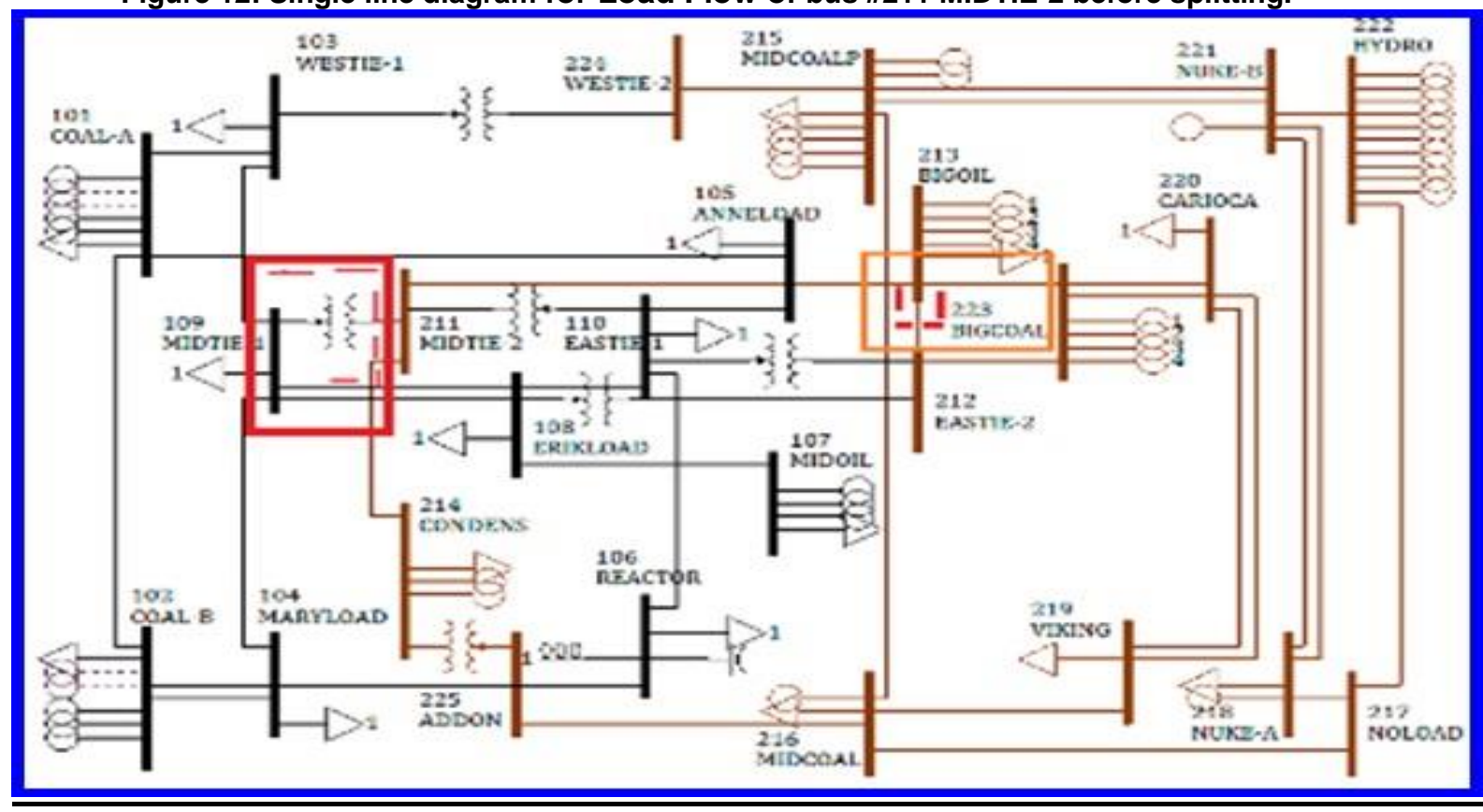

Figure 13: - single line diagram of IEEE 25-bus shown splitting position 
AL-QADISIYAH JOURNAL FOR ENGINEERING SCIENCES
Vol. 11, No. 3

ISSN: $1998-4456$

5. Determine the splitting choices for SBHSCL and make a table for all choices in Table (3).

6. Represent all points for all choices values of the Table (3) as in Figure (14).

7. Choose the optimal choice: The optimal choice is the two splitting positions in 211 and 212 buses known that the one splitting choice in 212 only is the optimum choice if the obligation for one split in the overall grid which have the minimum times of splitting and the lowest values of short circuit levels for SBHSCL and other substation in the system.

Table 3:- Three phase short circuit levels with splitting choices at 230KV side

\begin{tabular}{|c|c|c|c|c|c|c|c|c|}
\hline CHOICES & $\begin{array}{l}\text { Bus } \\
\text { Name }\end{array}$ & $\begin{array}{l}211 \\
\text { MIDTIE-2 }\end{array}$ & $\begin{array}{l}212 \\
\text { EASTIE-2 } \\
\end{array}$ & $\begin{array}{l}215 \\
\text { MIDCOALP }\end{array}$ & $\begin{array}{l}216 \\
\text { MIDCOAL }\end{array}$ & $\begin{array}{l}217 \\
\text { NOLOAD }\end{array}$ & $\begin{array}{l}\text { MIDTIE } \\
\text { SPLIT }\end{array}$ & $\begin{array}{l}\text { EASTIE } \\
\text { SPLT }\end{array}$ \\
\hline \multirow{2}{*}{ ORIGIN } & /I/ & 5.8712 & 5.7595 & 4.8443 & 5.292 & 4.5068 & & \\
\hline & $\angle \theta^{\circ}$ & -53.1132 & -50.2766 & -73.1827 & -83.956 & -56.2433 & & \\
\hline \multirow{2}{*}{$\begin{array}{c}\text { One SPLIT I in BUS \#211 } \\
\text { MIDTIE-2 }\end{array}$} & /I/ & 3.8065 & 5.7462 & 4.7839 & 5.1891 & 4.4773 & 3.6556 & \\
\hline & $\angle \theta^{\circ}$ & -33.1746 & -50.2264 & -72.9065 & -83.3439 & -56.1348 & -32.4257 & \\
\hline \multirow{2}{*}{$\begin{array}{l}\text { One SPLIT Iin BUS \#212 } \\
\text { EASTIE-2 }\end{array}$} & /I/ & 5.8804 & 4.7862 & 4.8125 & 5.2639 & 4.4966 & & 1.7909 \\
\hline & $\angle \theta^{\circ}$ & -50.0164 & -37.9543 & -73.0195 & -83.7538 & -56.2024 & & -16.4963 \\
\hline \multirow{2}{*}{$\begin{array}{c}\text { One SPLIT lin BUS \#211 } \\
\text { MIDTIE-2 AND One } \\
\text { SPLIT Iin BUS \#212 } \\
\text { EASTIE-2 } \\
\end{array}$} & /I/ & 3.8731 & 4.7836 & 4.8557 & 5.0275 & 4.4623 & 3.5348 & 1.7516 \\
\hline & $\angle \theta^{\circ}$ & -32.543 & -37.9405 & -49.3434 & -60.8985 & -56.0804 & -30.4554 & -16.348 \\
\hline
\end{tabular}

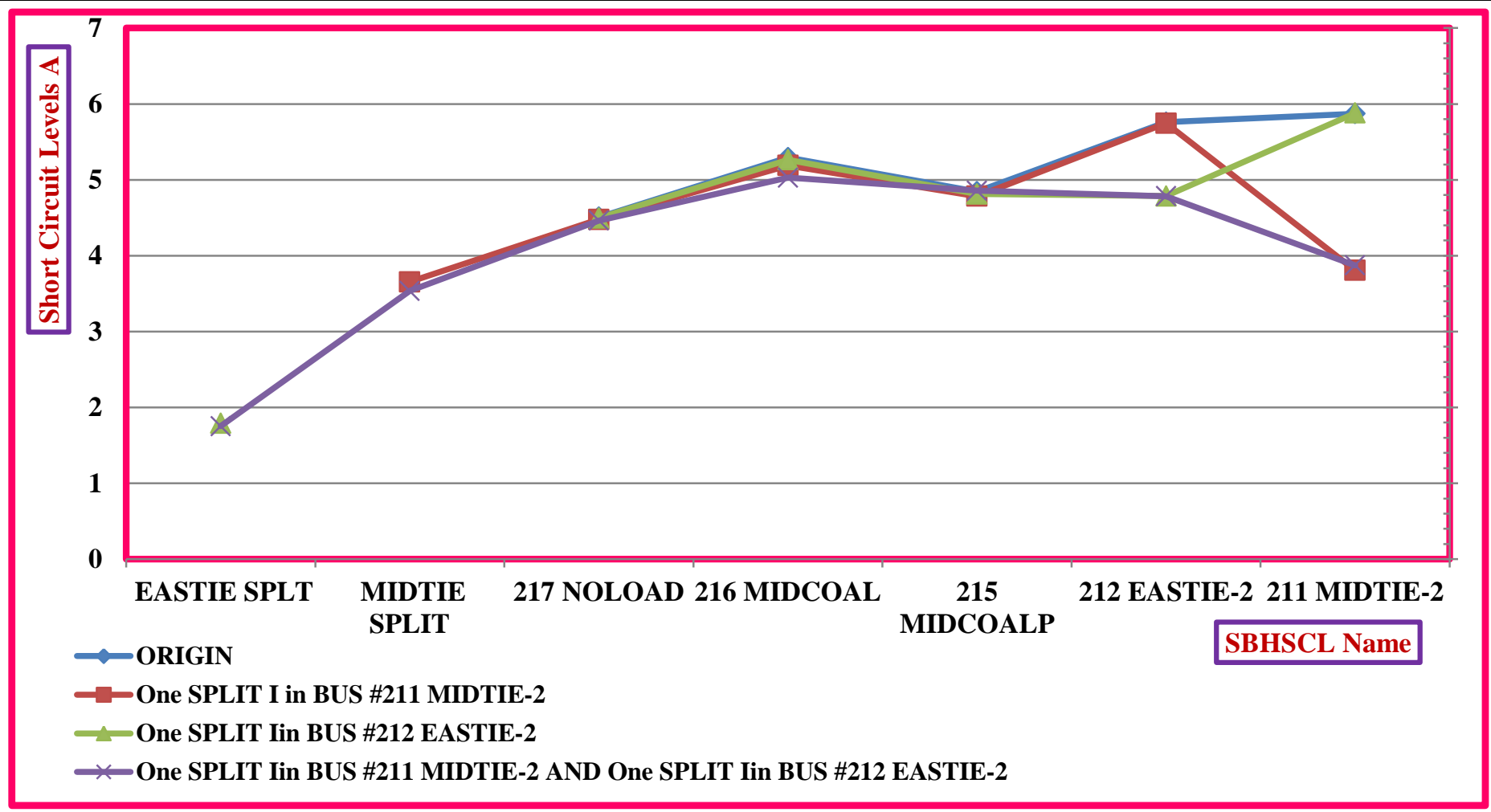

Figure(14): Three Phase Short Circuit Levels with New Proposed Splitting Strategies Choices for IEEE 25-Bus System. 


\section{AL-QADISIYAH JOURNAL FOR ENGINEERING SCIENCES}

Vol. 11 , No. 3

ISSN: $1998-4456$

\subsection{CASE 2: THE PRACTICAL SYSTEM: -}

Using the same procedure of the proposed method illustrated in section (4) and (PSS ${ }^{\mathrm{TM}} \mathrm{E}$ version 30.3 PACKAGE PROGRAME), as follows: -

1. Check load flow tes for the grid using Newton Raphson Technique with flat condition.

2. Check the three and single short circuit faults analysis for the overall system busbars and concentrate on $400 \mathrm{kV}$ grid as a case study, and identify the SBHSCL, since the SBHSCL had short circuit levels higher than 23kA. The SBHSCL are (400KV AL-Ameen substation (4AMN)), (400kV Baghdad South power station (4BGS)), (400kV Basmayah power station (BSMG-1)), (400kV Baghdad East power station (4BGE)), (400kV Babil substation (BAB)),(400kV Musaiab hydro power station (MUSP)) and (400kV Kut power station (KUTP)). The (400kV AL-Ameen substation and Baghdad South power station (4BGS)) are the main problem because of the highest short circuit levels of the busbar substations higher than the short circuit levels of their equipment's or closely the maximum values.

Table (4):- Detail feeding current for fault at 400KV AL-AMEEN substation busbar

\begin{tabular}{|c|c|c|c|c|c|c|}
\hline \multirow{2}{*}{ Bus No. } & \multirow{2}{*}{ SUBSTATION } & \multirow{2}{*}{$\begin{array}{l}\text { VOLTAGE } \\
(\mathrm{KV})\end{array}$} & \multirow{2}{*}{$\begin{array}{c}\text { THREE } \\
/ \mathrm{I}+/ \\
\end{array}$} & \multirow{2}{*}{$\begin{array}{r}\text { PHASE FAULT } \\
\text { AN(I+) }\end{array}$} & \multicolumn{2}{|c|}{ ONE PHASE FAULT } \\
\hline & & & & & /IA/ & $\mathrm{AN}(\mathrm{IA})$ \\
\hline 16419 & 4BGS & 400.00 & 6064 & -86.16 & 5202 & -82.79 \\
\hline 16428 & 4BGE & 400.00 & 5828.3 & -86.24 & 5534.8 & -83.27 \\
\hline 16471 & BSMG-1 & 400.00 & 7854.2 & -86.06 & 7507.8 & -84.16 \\
\hline 17403 & 4DAL & 400.00 & 2983.9 & -85.9 & 2673.6 & -82.94 \\
\hline 18406 & KUTP & 400.00 & 4245.2 & -85.53 & 3525.4 & -82.67 \\
\hline 18406 & KUTP & 400.00 & 4245.2 & -85.53 & 3525.4 & -82.67 \\
\hline 3WNDTR & & WND 1 & 678.7 & -88.64 & 1038.3 & -90 \\
\hline 3WNDTR & & WND 1 & 678.7 & -88.64 & 1038.3 & -90 \\
\hline 3WNDTR & & WND 1 & 0 & 0 & 497.1 & -89.78 \\
\hline 3WNDTR & & WND 1 & 0 & 0 & 497.1 & -89.78 \\
\hline \multicolumn{3}{|c|}{ TOTAL FAULT CURRENT } & 32576.5 & -86.07 & 31019.3 & -83.9 \\
\hline
\end{tabular}

Table (5):- Detail feeding current for fault at $400 \mathrm{kV}$ Baghdad South power station busbar

\begin{tabular}{|c|c|c|c|c|c|c|}
\hline \multirow{2}{*}{ Bus No. } & \multirow{2}{*}{ SUBSTATION } & \multirow{2}{*}{$\begin{array}{l}\text { VOLTAGE } \\
\quad(\mathrm{KV})\end{array}$} & \multicolumn{2}{|c|}{ THREE PHASE FAULT } & \multicolumn{2}{|c|}{ ONE PHASE FAULT } \\
\hline & & & $/ \mathrm{I}+1$ & $\mathrm{AN}(\mathrm{I}+)$ & /IA/ & $\mathrm{AN}(\mathrm{IA})$ \\
\hline 16443 & $4 \mathrm{AMN}$ & 400 & 6288.3 & -85.95 & 5359.5 & -82.89 \\
\hline 16470 & 4BGC & 400 & 3889.5 & -85.79 & 3843.7 & -83.84 \\
\hline 16471 & BSMG-1 & 400 & 11282.5 & -86.62 & 11427.4 & -85.16 \\
\hline 20401 & MUSP & 400 & 6342.4 & -85.82 & 6395.9 & -83.66 \\
\hline 23402 & 4KDS & 400 & 2892.9 & -85.63 & 2371.2 & -82.57 \\
\hline 3WNDTR & & WND 1 & 389.1 & -85.89 & 573 & -88.18 \\
\hline 3WNDTR & & WND 1 & 389.1 & -85.89 & 573 & -88.18 \\
\hline 3WNDTR & & WND 1 & 389.1 & -85.89 & 573 & -88.18 \\
\hline \multicolumn{3}{|c|}{ TOTAL FAULT CURRENT (Ampere) } & 31862.2 & -86.11 & 31108.5 & -84.27 \\
\hline
\end{tabular}




\section{AL-QADISIYAH JOURNAL FOR ENGINEERING SCIENCES}

Vol. 11 , No. 3

ISSN: $1998-4456$

3. At the same time get a table about the fault feeding currents for each busbar of (400KV AL-Ameen substation), (400KV Baghdad South power station) during the fault as in tables (4 and 5) sequentially.

4. From the Figure (15) shows single line diagram of Al-Ameen substation with load flow determine the number of splitting choices to complete the procedure of the new proposed splitting strategies such that, the (16443 4AMN) busbar in figure (15) supplied six transmission lines with the (16419 (4BGS), 16428 (4BGE), 16471 (BSMG-1), 17403 (4DAL), and two lines with (18406) (KUTP)) stations and four power transformers (1,2,3 and 4), which divided electrically into two sections busbars (16443 and 16888) as shown in Figures (16 and 17) for choice 1) and ((19 and 20) for choice 2)) sequentially.

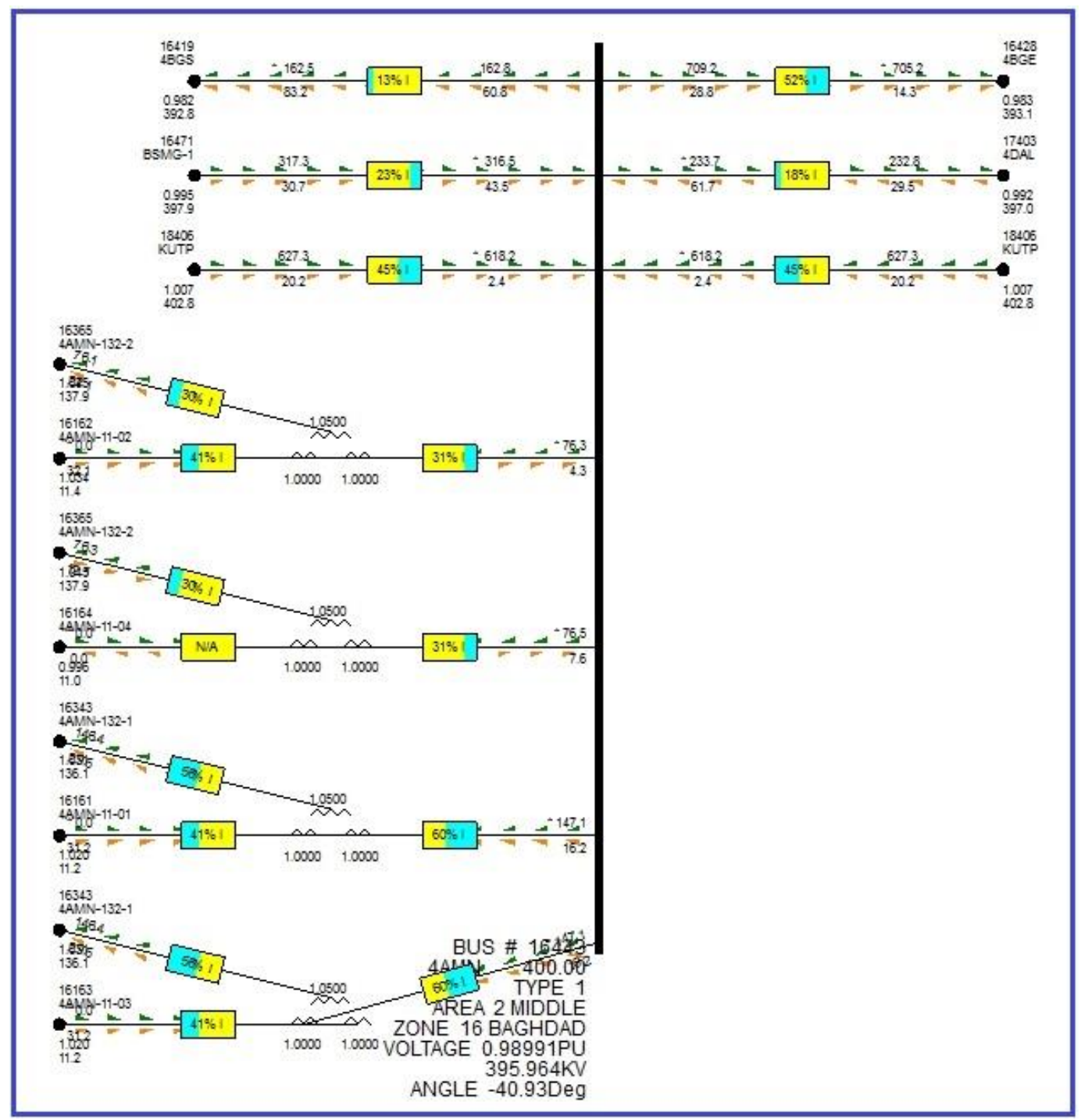

Figure (15): - Single line diagram of Al-Ameen substation with load flow.

The procedure of choice is depending on load flow analysis, such that the power values to be minimum at splitting point before splitting as in Figures (18 for choice 1) and ((21) for choice 2)) and the values of infeed fault power in Table (4) of the transmission lines with busbars (16419 (4BGS)), (16428 (4BGE)), (16471 (BSMG-1)), (17403 (4DAL)), and two line with (18406) (KUTP)) must give opinion of distributing transmission lines on busbars (16443 and 16888) by this procedure, then have several choices, after checking the successful choices in load flow analysis for each choice may take the successful choices, where, in this case the details of successful choices are two choices as following: 


\section{AL-QADISIYAH JOURNAL FOR ENGINEERING SCIENCES}

Vol. 11 , No. 3

ISSN: 1998-4456

\section{One splitting in AMN choice1:}

(16443 busbar) supplied three transmission lines with (16428 (4BGE)), (16471 (BSMG-1) busbars)) and one line with (18406) (KUTP)) and two power transformers (1 and 2), furthermore, (16888) busbar supplied three transmission lines with (16419 (4BGS)), (17403 (4DAL) busbars) and one line with (18406 KUTP) and two power transformers (3 and 4) as Figures (19 and 20).

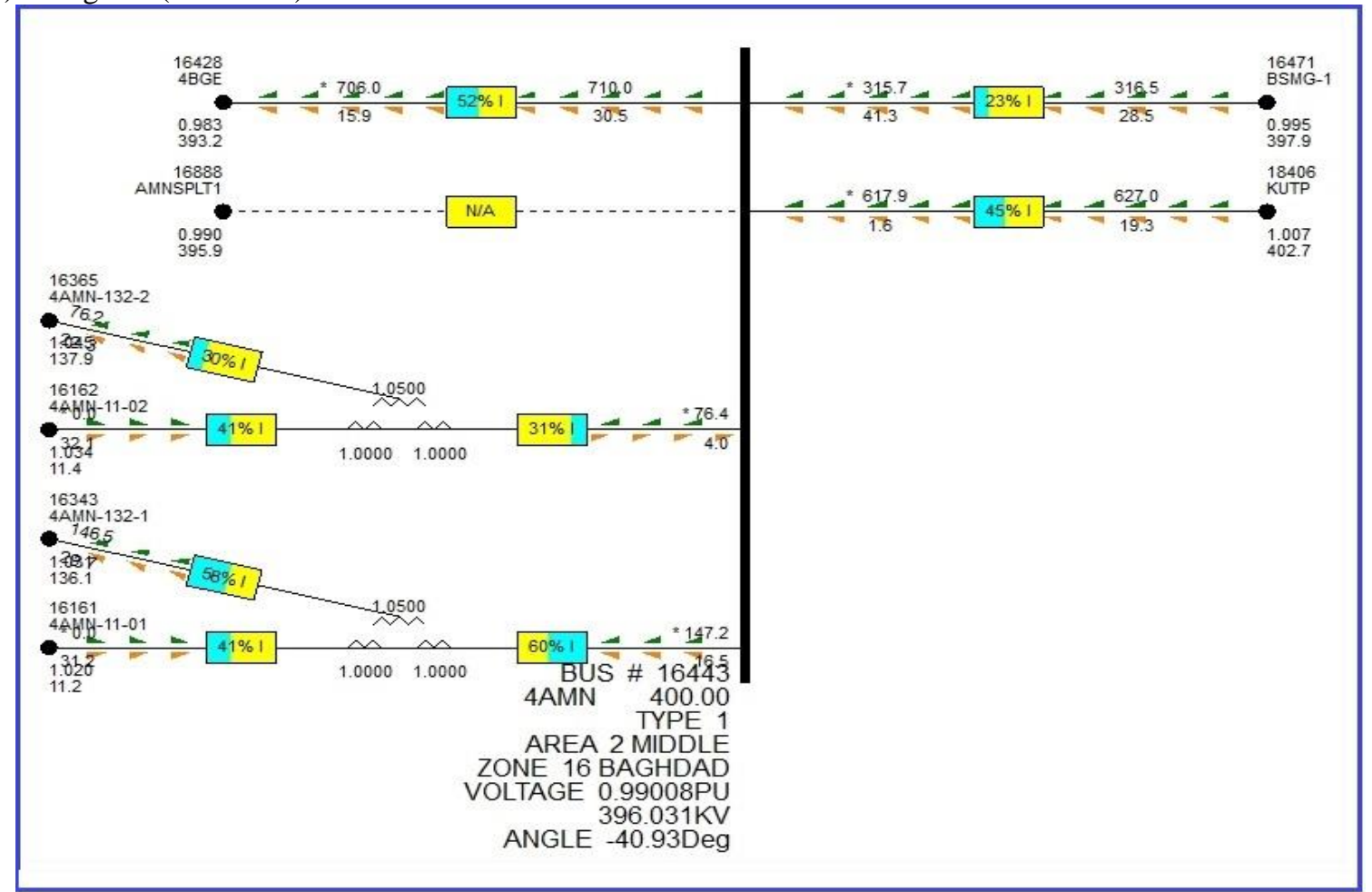

Figure (16): Single line diagram of Al-Ameen substation for (16443 bus) after splitting choice 1.

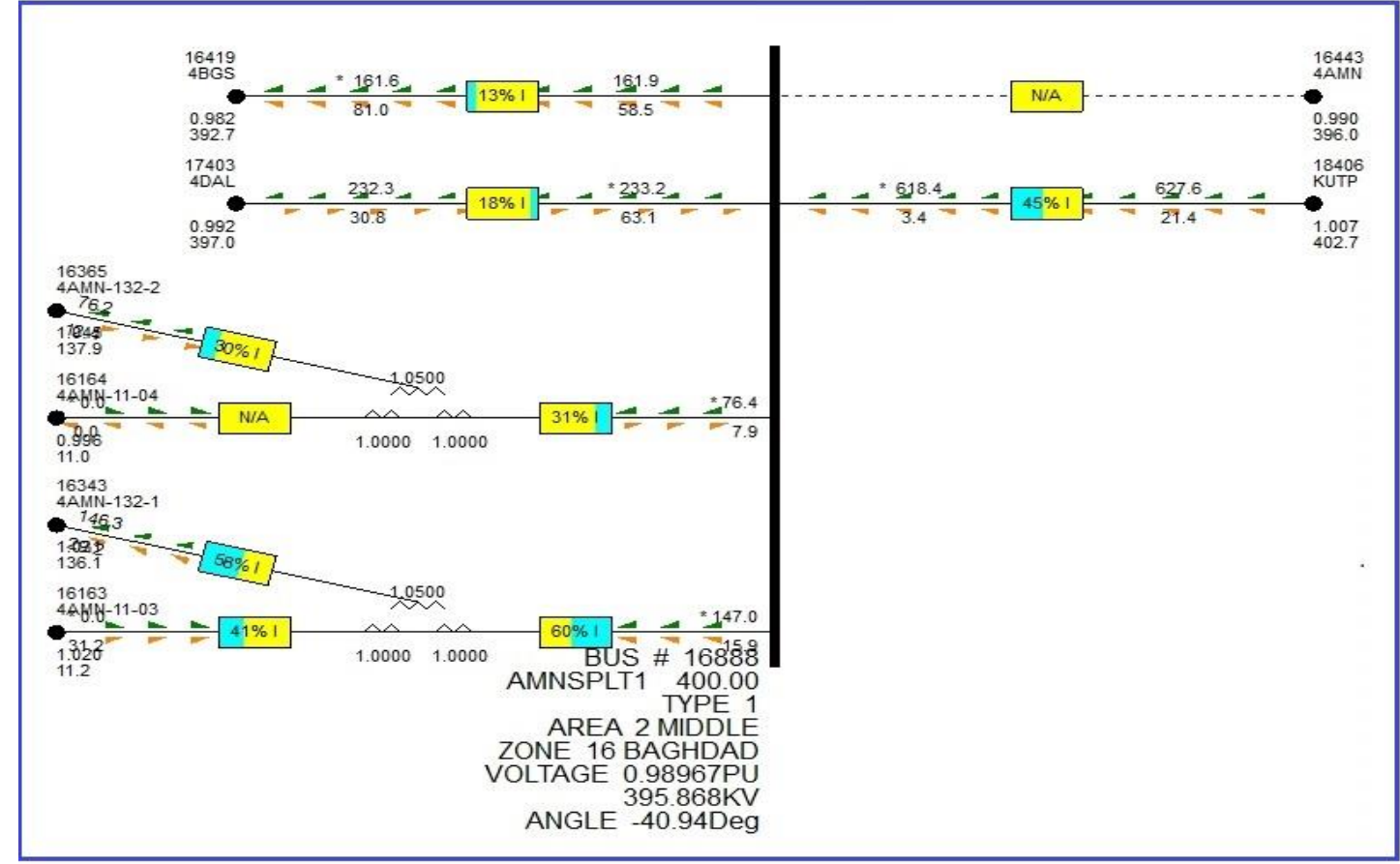

Figure (17): Single line diagram of Al-Ameen substation for (16888 bus) after splitting choice 1. 


\section{AL-QADISIYAH JOURNAL FOR ENGINEERING SCIENCES}

Vol. 11, No. 3

ISSN: $1998-4456$

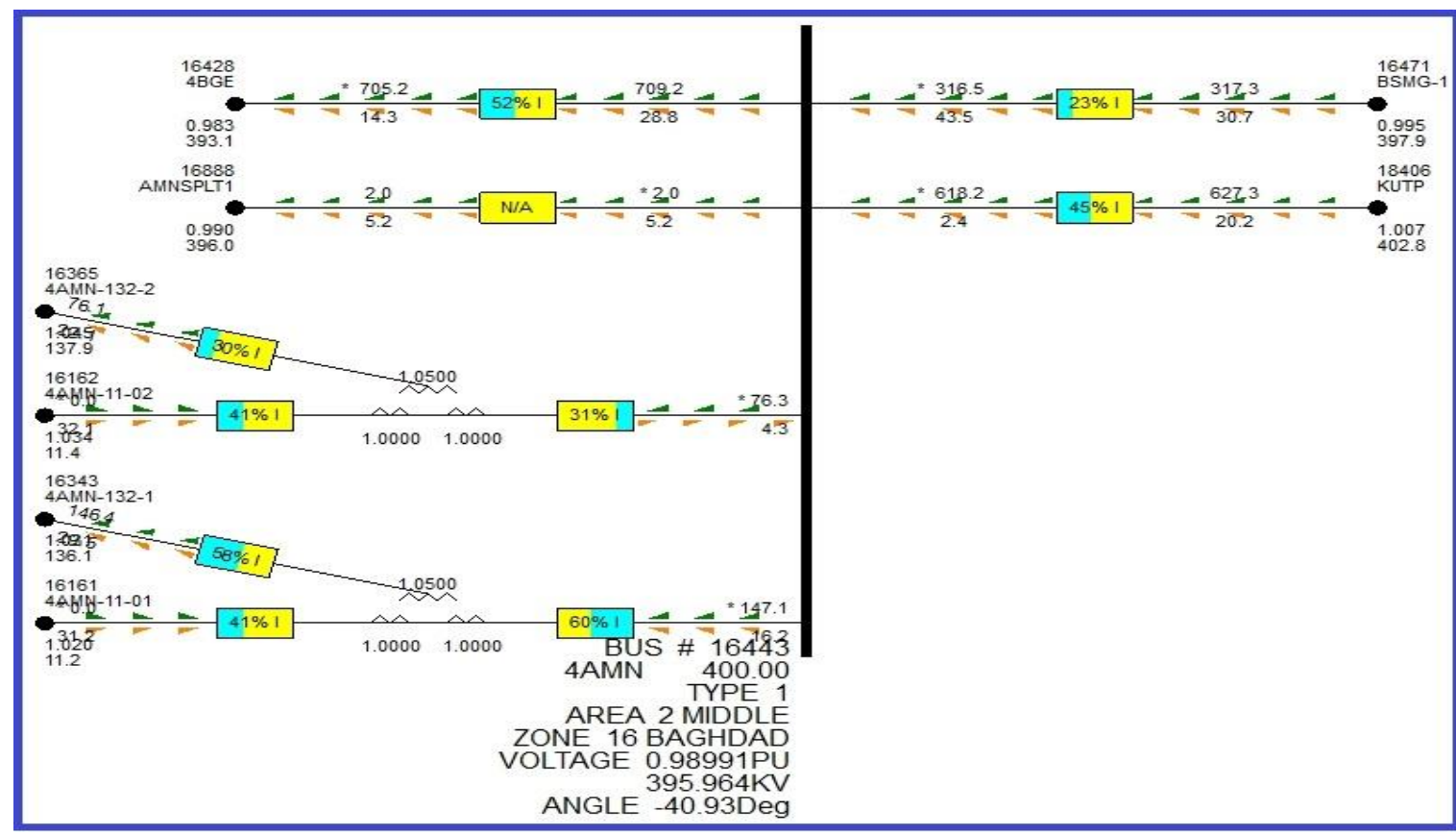

Figure (18): Single line diagram of Al-Ameen substation for (16443 bus) before splitting choice 1.

One splitting in AMN choice2: (16443 busbar) supplied four transmission lines with (16428 (4BGE)), (17403 (4DAL)) and two lines with (18406 KUTP) and two power transformers (1 and 3), furthermore, (16888 busbar) supplied two transmission lines with (16419 (4BGS)) and (16471 (BSMG-1) busbars) and two power transformers (2 and 4) as shown in Figures (19 and 20).

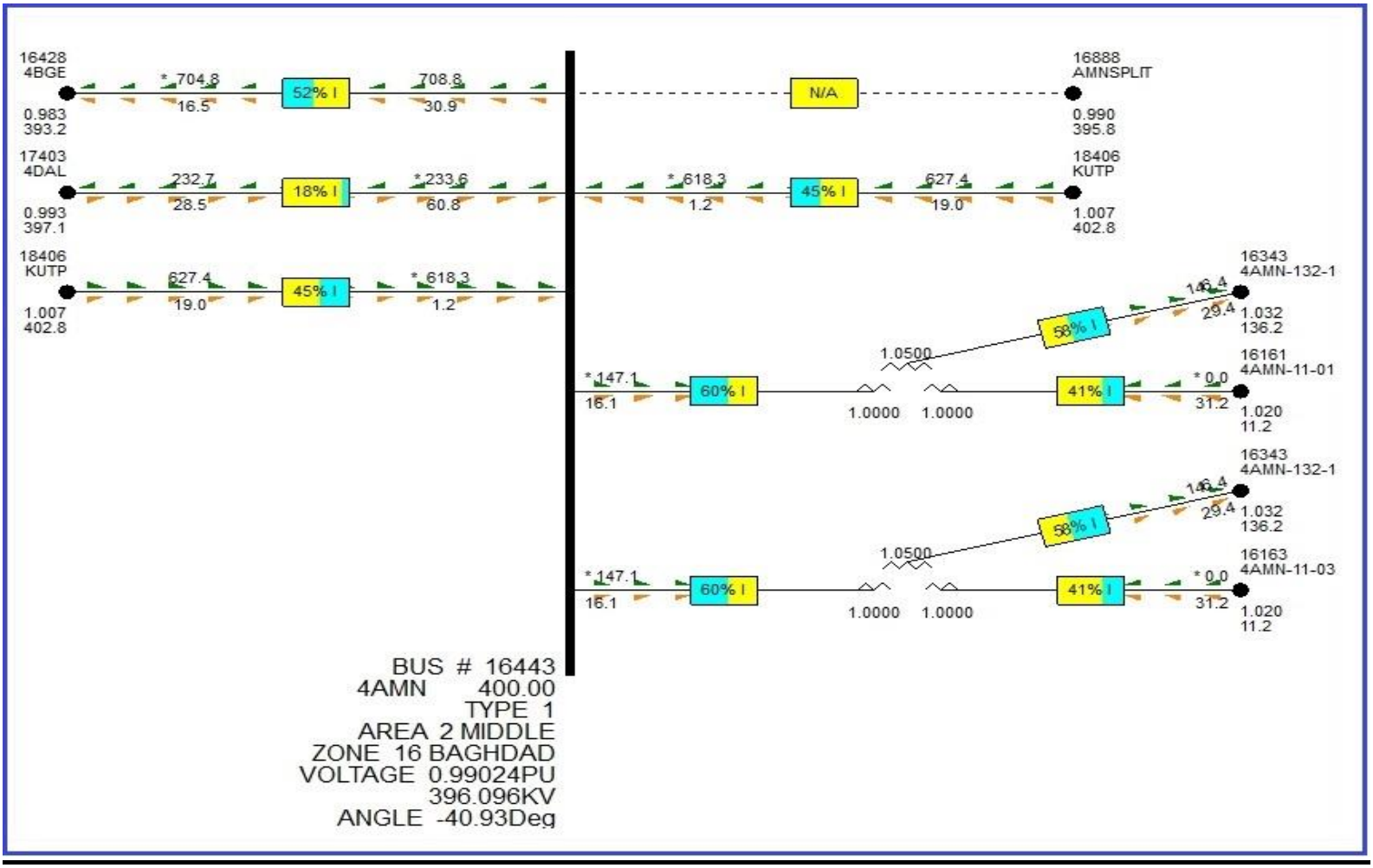

Figure (19): Single line diagram of Al-Ameen substation for (16443 bus) after splitting choice 2. 


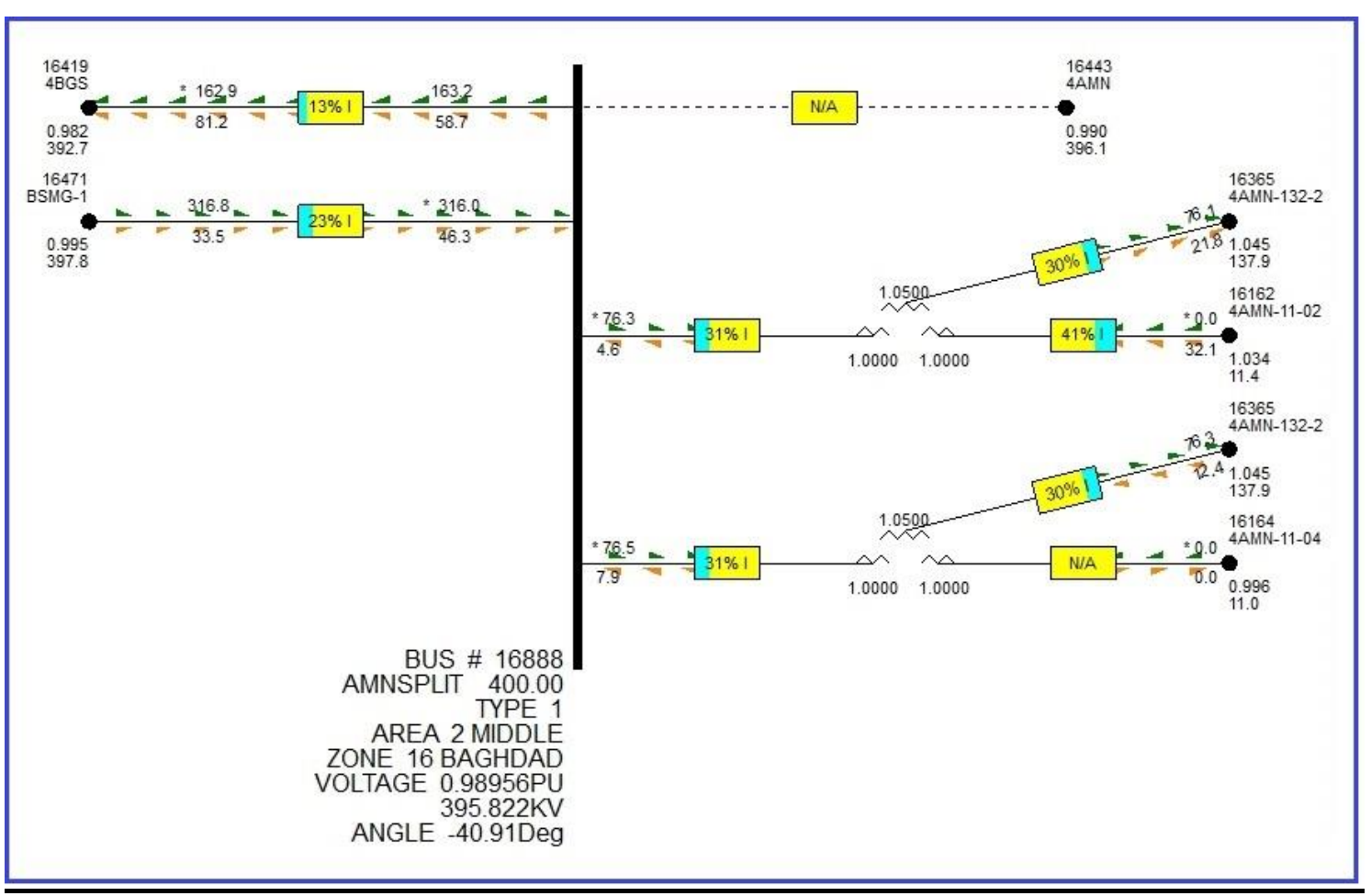

Figure (20): Single line diagram of Al-Ameen substation for (16888 bus) after splitting choice 2.

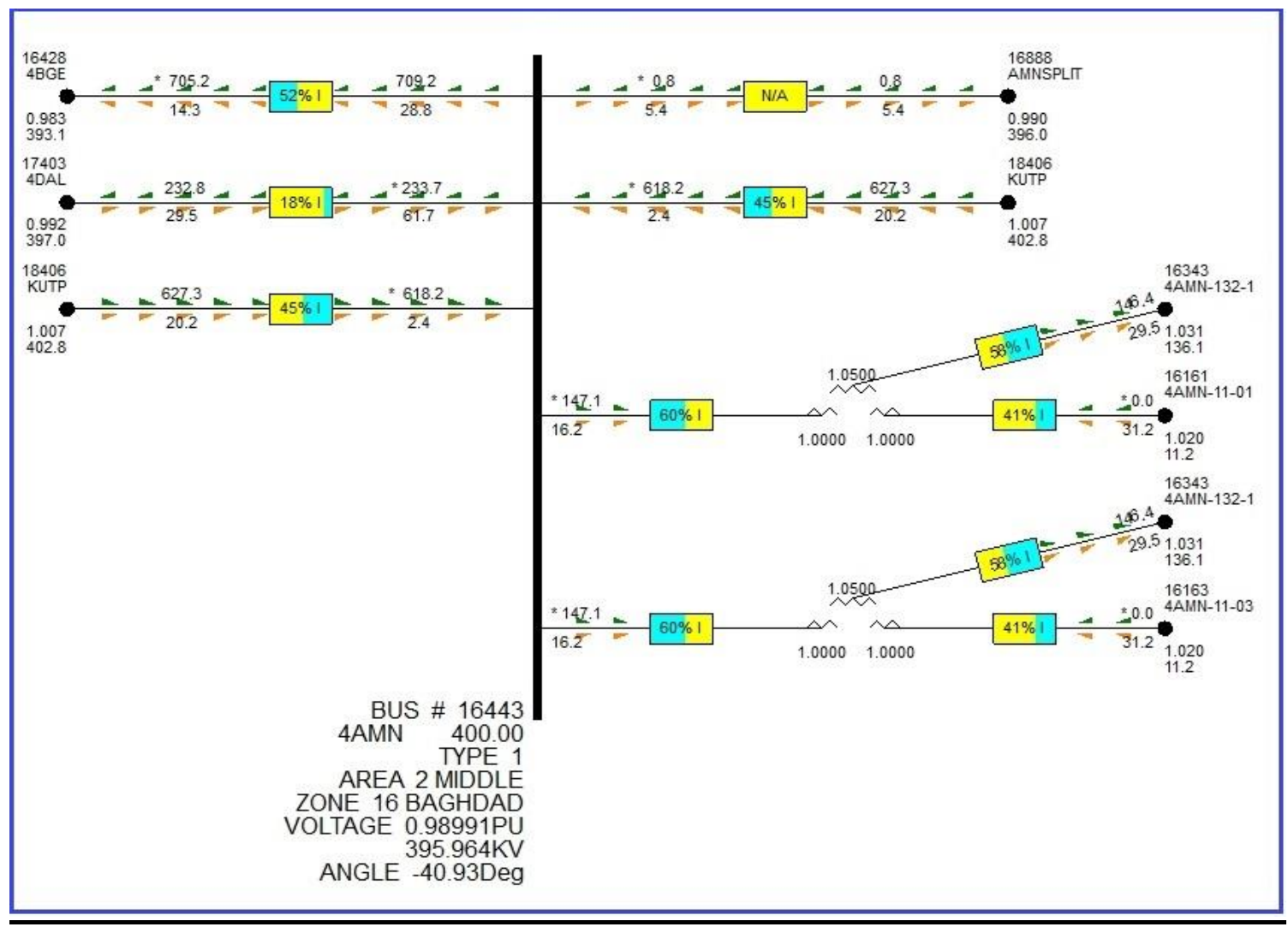

Figure (21): Single line diagram of Al-Ameen substation for ( 16443 bus) before splitting choice 2. 


\section{AL-QADISIYAH JOURNAL FOR ENGINEERING SCIENCES}

Vol. 11 , No. 3

ISSN: $1998-4456$

\section{Baghdad South substation (4BGS):}

Figure (22) shows single line diagram of Baghdad South substation with load flow determines number of splitting choices to complete the procedure of the new proposed splitting strategies such that, the (16419 (4BGS) busbar in Figure (22) supplied five transmission lines with the (16443 (4AMN), 16470 (4BGC) and 16471 (BSMG-1)) stations and four power transformers (1,2,3 and 4), which divided electrically into two sections busbars (16419 and 16777) shown in Figure (23 and 24) for choice (1) and (26 and 27) for choice (2).

The procedure of choice is depending on load flow analysis, such that the power values to be minimum at splitting point before splitting as in figures (25 for choice 1) and ((28) for choice 2). The values of infeed fault currents in Table (4.6) of the transmission lines with busbars ((16443 (4AMN), 16470 (4BGC), 16471 (BSMG-1), (20401 (MUSP)) and (23402(4KDS)) must give opinion of distributing transmission lines on busbars (16419 and 16777) by this procedure, then have several choices, after checking the successful choices in load flow analysis for each choice may take the successful choices, where, in this case the details of successful choices are two choices as following:

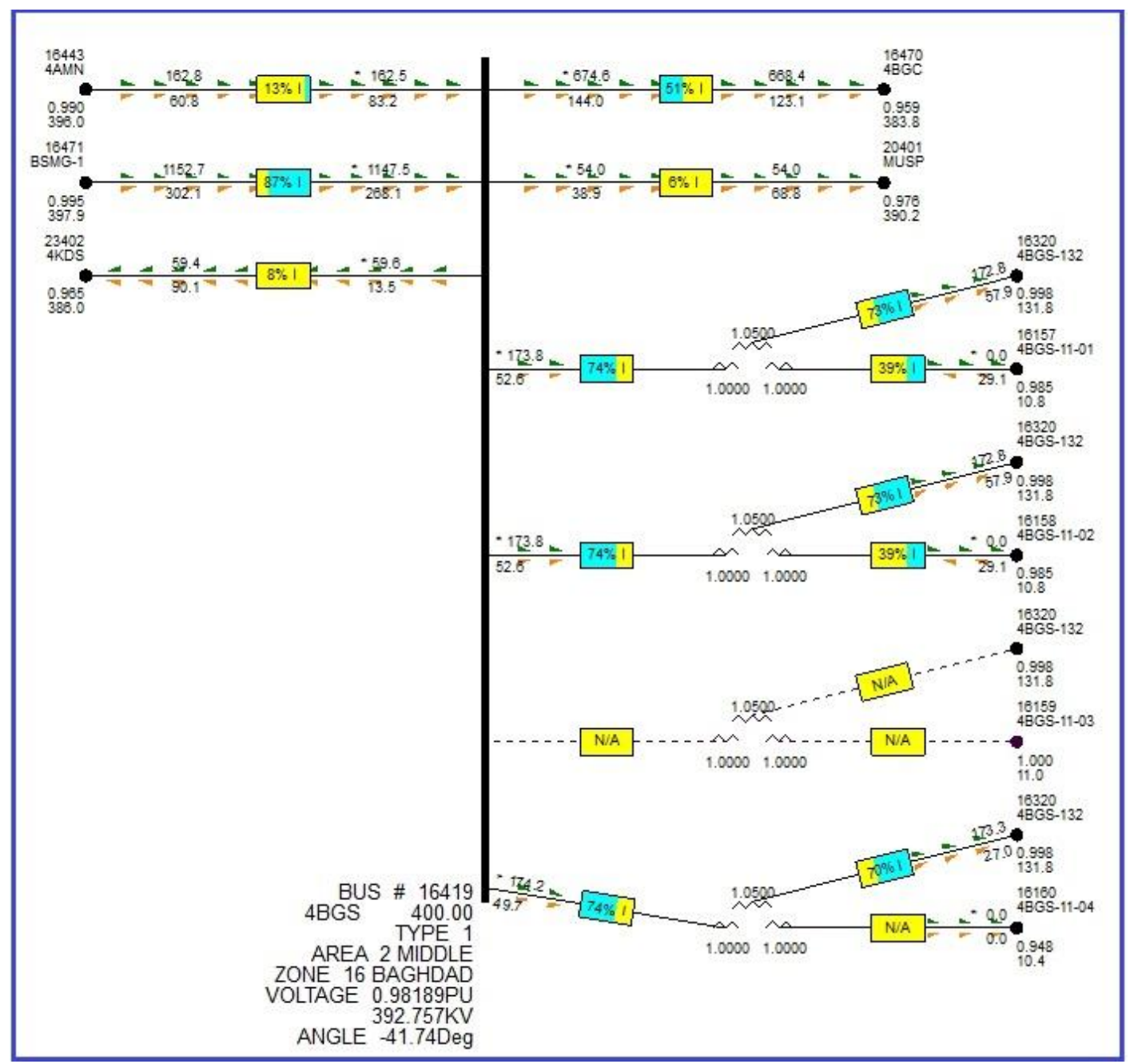

Figure (22): Single line diagram of Baghdad South substation with load flow

One splitting in BGS choice1 (16419 busbar) supplied two transmission lines with (16470 (4BGC)), 16471 (BSMG1) busbars) and four power transformers (1,2,3 and 4), furthermore, 16777 busbar supplied three transmission line with (16443 (4AMN)), 20402 (4MUSP) and (23402 (4KDS)) as in Figures ((23) and (24)). 


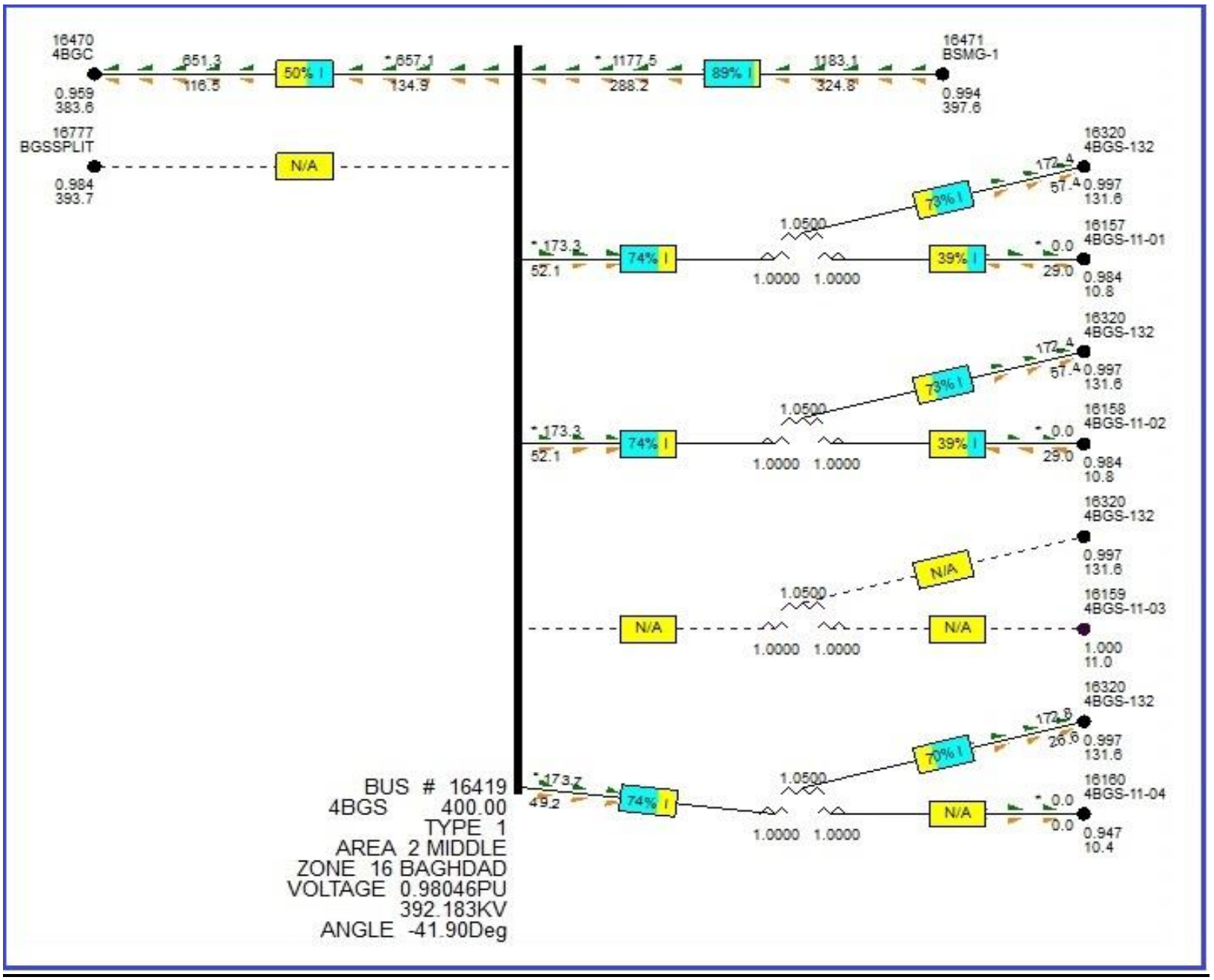

Figure (23): Single line diagram of Baghdad South power station for (16419 bus) after splitting choice 1.

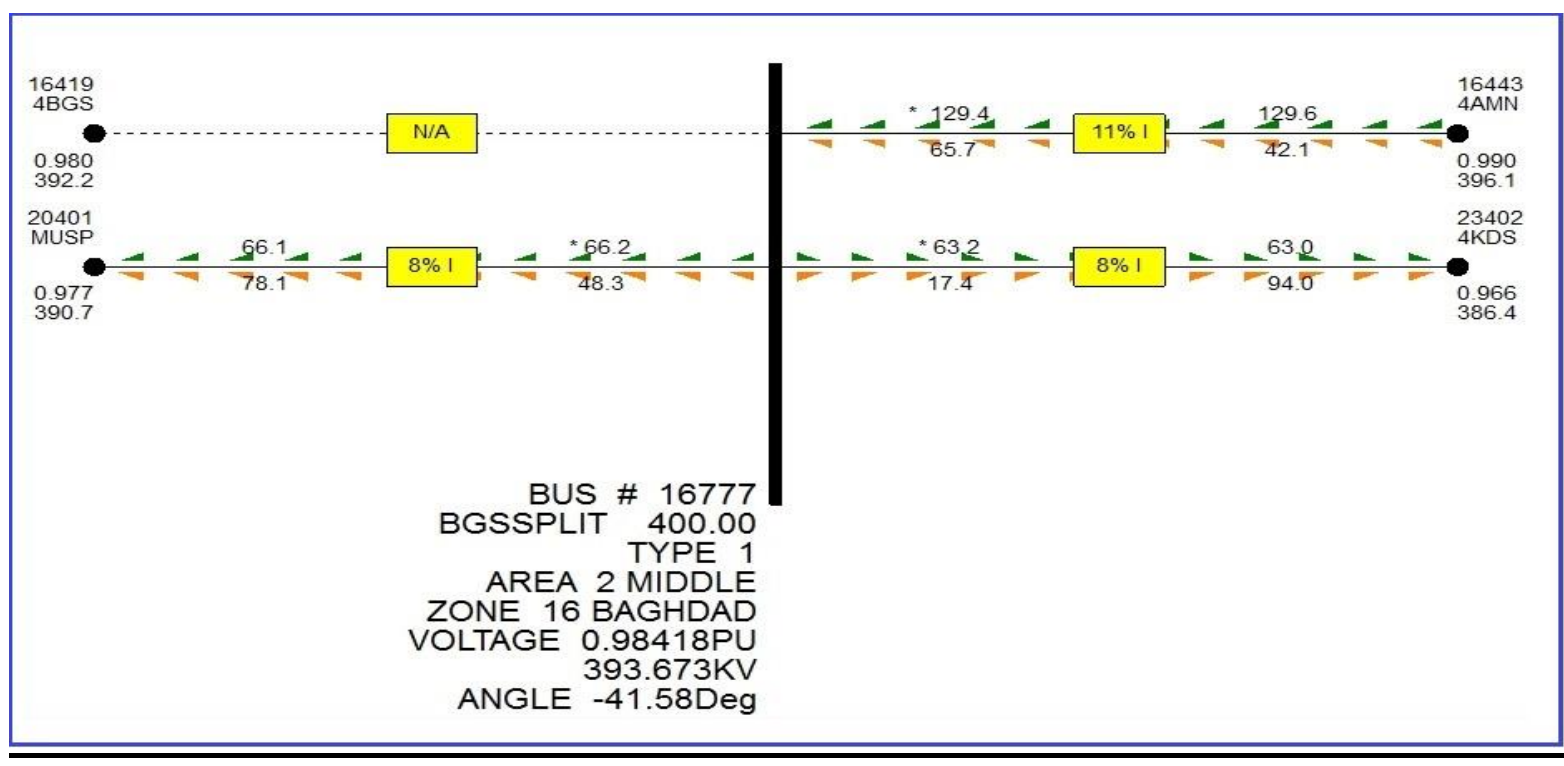

Figure (24): Single line diagram of Baghdad South power station for (16777 bus) after splitting choice 1. 

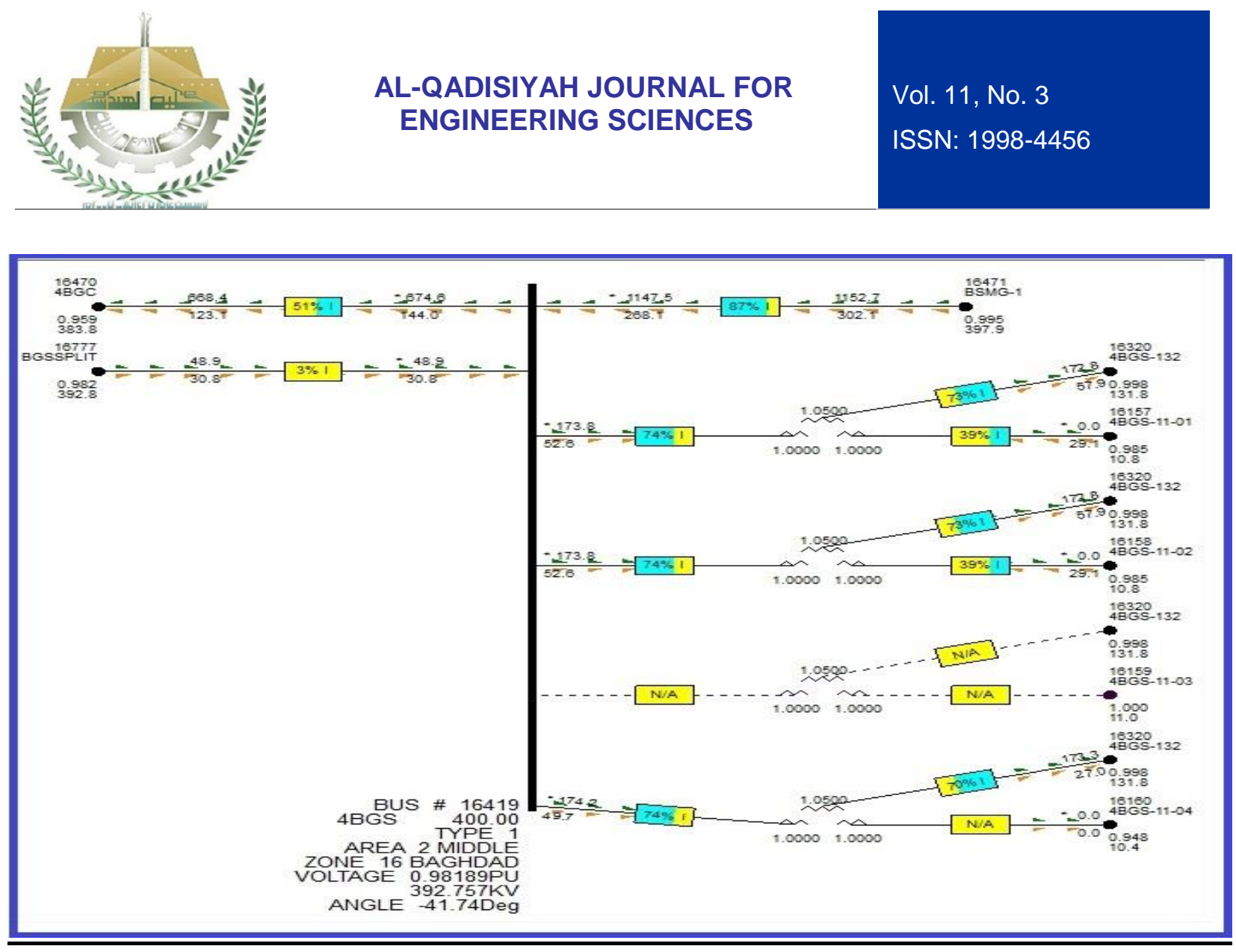

Figure (25): Single line diagram of Baghdad South power station for (16419 bus) before splitting choice 1.

One splitting in BGS choice2

(16419 busbar) supplies three transmission lines with (16470 (4BGC)), (16471 (BSMG-1) busbars and (23402 (4KDS)) ) and three power transformer (2,3 and 4), furthermore, (16777 busbar) supply two transmission line with (16443 (4AMN)) and (20402 (4MUSP)), and one power transformer (1) as in figures (26 and 27).

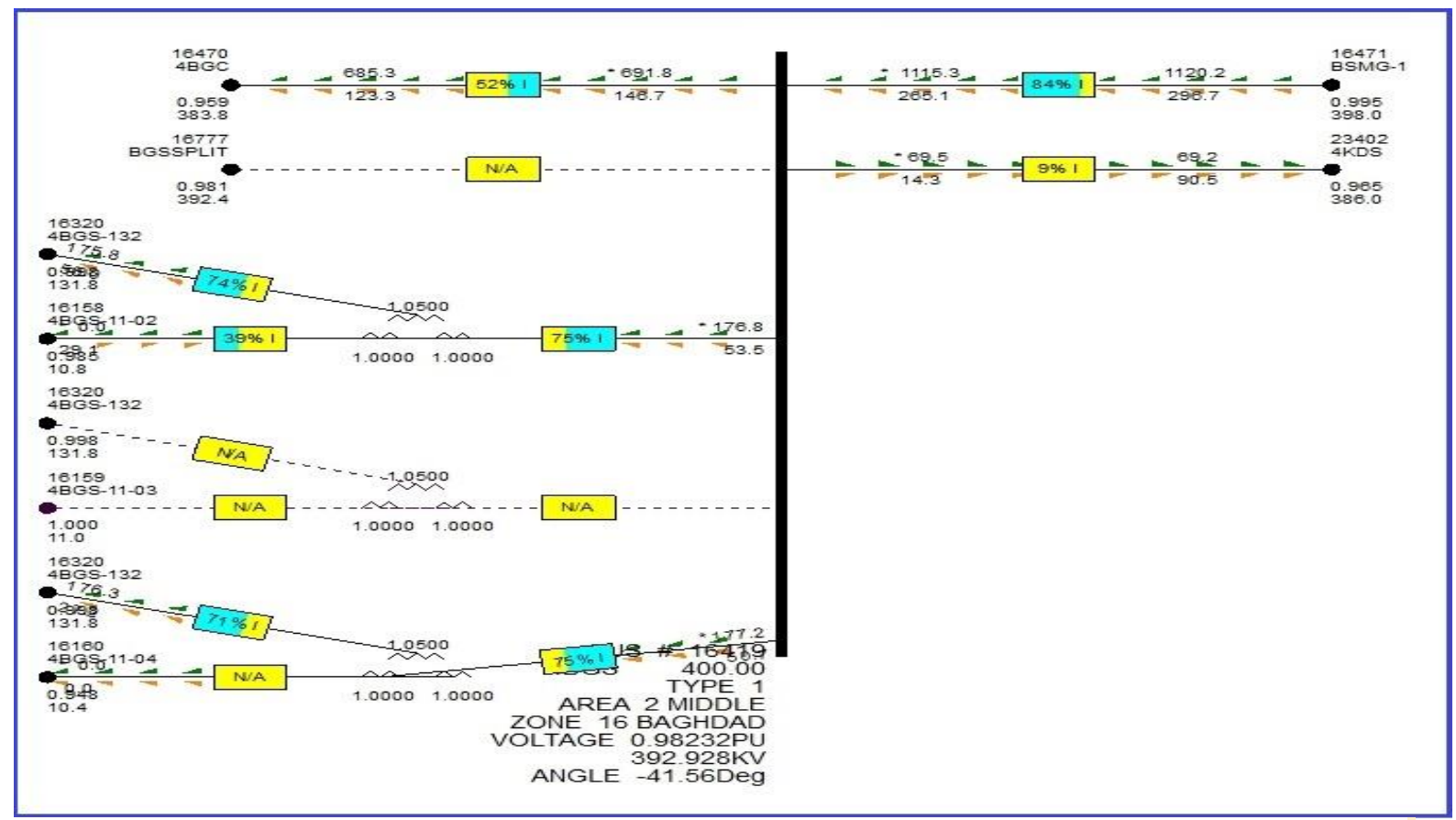

Figure (26): Single line diagram of Baghdad South power station for (16419 bus) after splitting choice 2. 


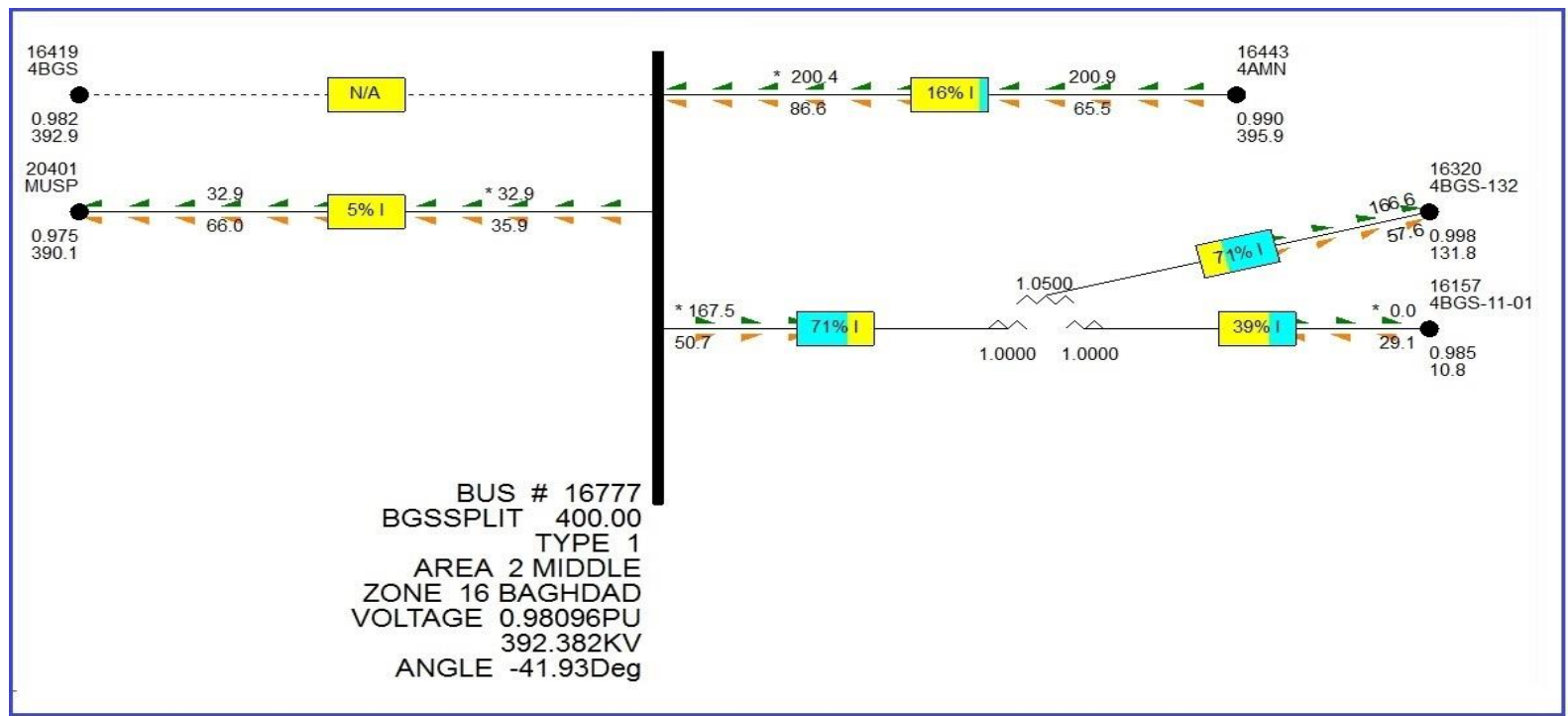

Figure (27): Single line diagram of Baghdad South power station for (16777 bus) after splitting choice 2.

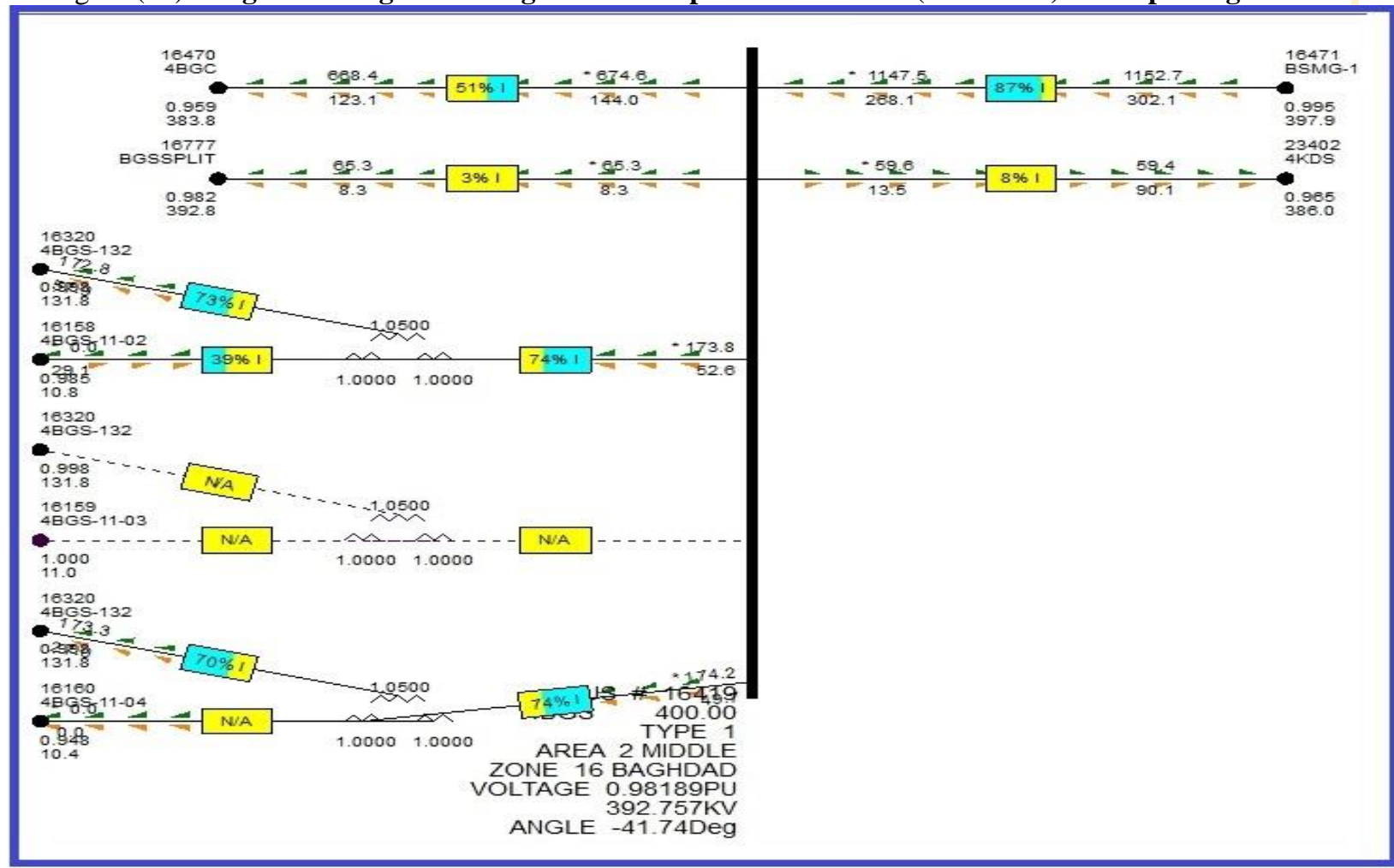

Figure (28): Single line diagram of Baghdad south power station for (16443 bus) before splitting choice 2.

5. Check the short circuit test for each choice and make table for three and single phase control splitting of all choices results mention above, as in Tables ((6) and (7)) sequentially.

6. Represented the values of all choices table (6) as in figure (29).

7. Represent the values of all choices table (7) as in Figure (30). 


\section{AL-QADISIYAH JOURNAL FOR ENGINEERING SCIENCES}

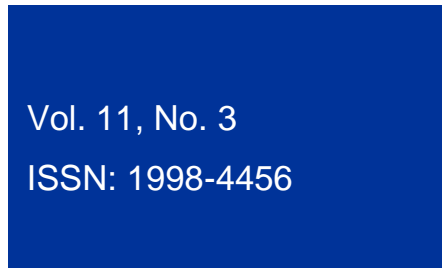

Table (6) :Three Phase Short Circuit Levels in (A) for Iraqi Power Grid with New Proposed Splitting Strategies Method Choices

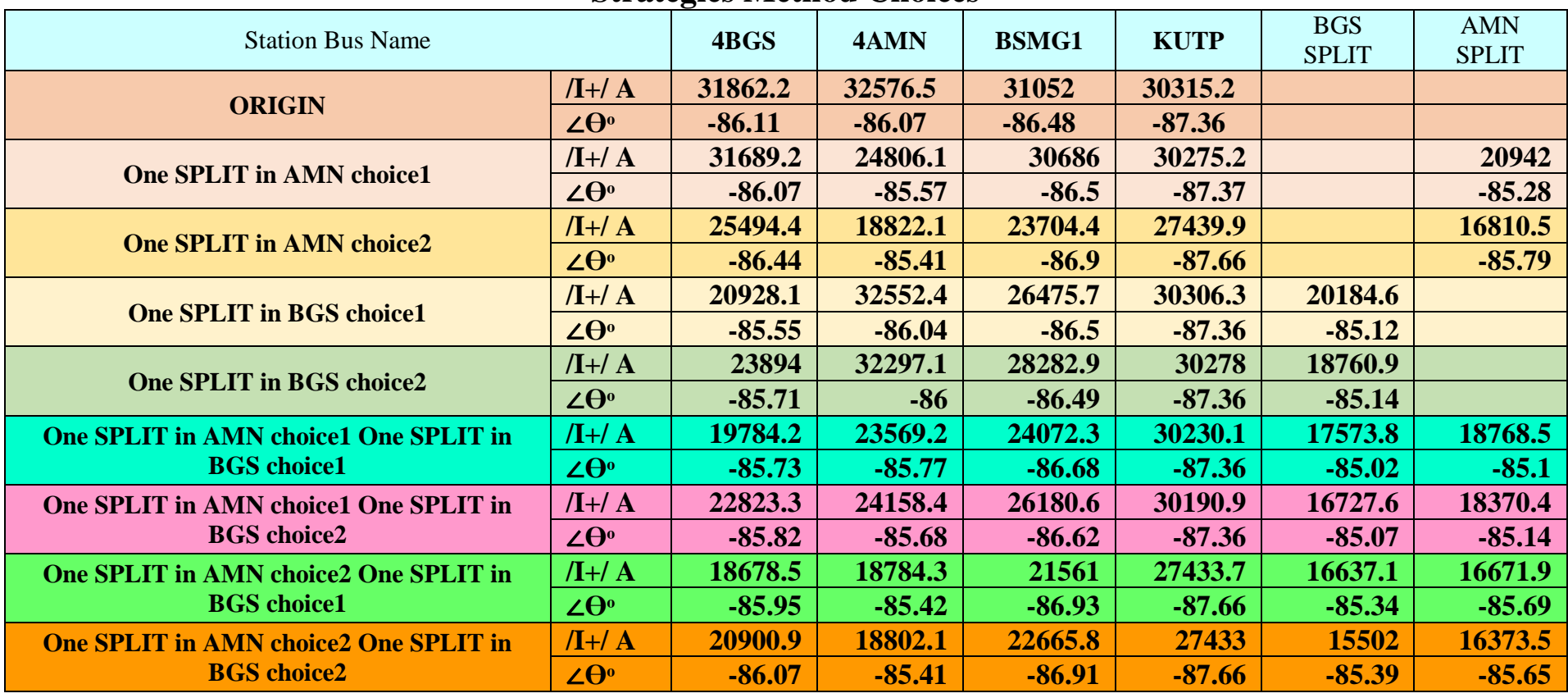

Table (7) :Single Phase Short Circuit Levels in (A) for Iraqi Power Grid with New Proposed Splitting Strategies Method Choices

\begin{tabular}{|c|c|c|c|c|c|c|c|}
\hline \multicolumn{2}{|l|}{ Station Bus Name } & 4BGS & 4AMN & BSMG1 & KUTP & BGS SPLIT & AMN SPLIT \\
\hline \multirow{2}{*}{ ORIGIN } & $|\mathbf{I}|$ & 31108.5 & 31019.3 & 33291.5 & 33674.4 & & \\
\hline & $\boldsymbol{\theta}^{\circ}$ & -84.27 & -83.9 & -86.33 & -87.53 & & \\
\hline \multirow{2}{*}{ One SPLIT in AMN choice1 } & $|\mathbf{I}|$ & 30897.7 & 22371.8 & 32903.2 & 33634.6 & & 17217.7 \\
\hline & $\boldsymbol{\theta}^{\circ}$ & -84.26 & -83.47 & -86.35 & -87.53 & & -82.44 \\
\hline \multirow{2}{*}{ One SPLIT in AMN choice2 } & $|\mathbf{I}|$ & 26171.6 & 17098.2 & 26593.4 & 31106.1 & & 15720.4 \\
\hline & $\boldsymbol{\theta}^{\circ}$ & -85.01 & -82.83 & -86.97 & -87.81 & & -84.1 \\
\hline \multirow{2}{*}{ One SPLIT in BGS choice1 } & $|\mathbf{I}|$ & 20189.8 & 30879 & 28960.3 & 33665 & 16623.2 & \\
\hline & $\boldsymbol{\theta}^{\circ}$ & -84.35 & -83.86 & -86.58 & -87.52 & -81.46 & \\
\hline \multirow{2}{*}{ One SPLIT in BGS choice2 } & $|\mathrm{I}|$ & 28575.6 & 28742.3 & 23463.2 & 33386.2 & & \\
\hline & $\boldsymbol{\theta}^{\circ}$ & -84.4 & -83.99 & -86 & -87.57 & & \\
\hline \multirow{2}{*}{$\begin{array}{l}\text { One SPLIT in AMN choice1 One } \\
\text { SPLIT in BGS choice1 }\end{array}$} & $|\mathbf{I}|$ & 19392.8 & 21623.3 & 26736.7 & 33592.4 & 14801.2 & 15574.7 \\
\hline & $\boldsymbol{\theta}^{\circ}$ & -84.57 & -83.72 & -86.82 & -87.53 & -81.83 & -82.64 \\
\hline \multirow{2}{*}{$\begin{array}{l}\text { One SPLIT in AMN choice1 One } \\
\text { SPLIT in BGS choice2 }\end{array}$} & $|\mathbf{I}|$ & 21371.1 & 21949.3 & 28461.5 & 33561.4 & 14979.3 & 15485.4 \\
\hline & $\theta^{\circ}$ & -84.21 & -83.63 & -86.7 & -87.53 & -83.19 & -82.8 \\
\hline \multirow{2}{*}{$\begin{array}{l}\text { One SPLIT in AMN choice2 One } \\
\text { SPLIT in BGS choice1 }\end{array}$} & $|\mathrm{I}|$ & 18600 & 17077.4 & 24383.8 & 31100.9 & 14476.7 & 15498.6 \\
\hline & $\boldsymbol{\theta}^{\circ}$ & -84.83 & -82.84 & -87.11 & -87.81 & -82.18 & -84.01 \\
\hline \multirow{2}{*}{$\begin{array}{l}\text { One SPLIT in AMN choice2 One } \\
\text { SPLIT in BGS choice2 }\end{array}$} & $|\mathbf{I}|$ & 20086.1 & 17087.1 & 25307 & 31100.2 & 14370.8 & 15357.7 \\
\hline & $\boldsymbol{\theta}^{\circ}$ & -84.53 & -82.83 & -87.04 & -87.81 & -83.49 & -84.07 \\
\hline
\end{tabular}




\section{AL-QADISIYAH JOURNAL FOR ENGINEERING SCIENCES}

Vol. 11 , No. 3

ISSN: $1998-4456$

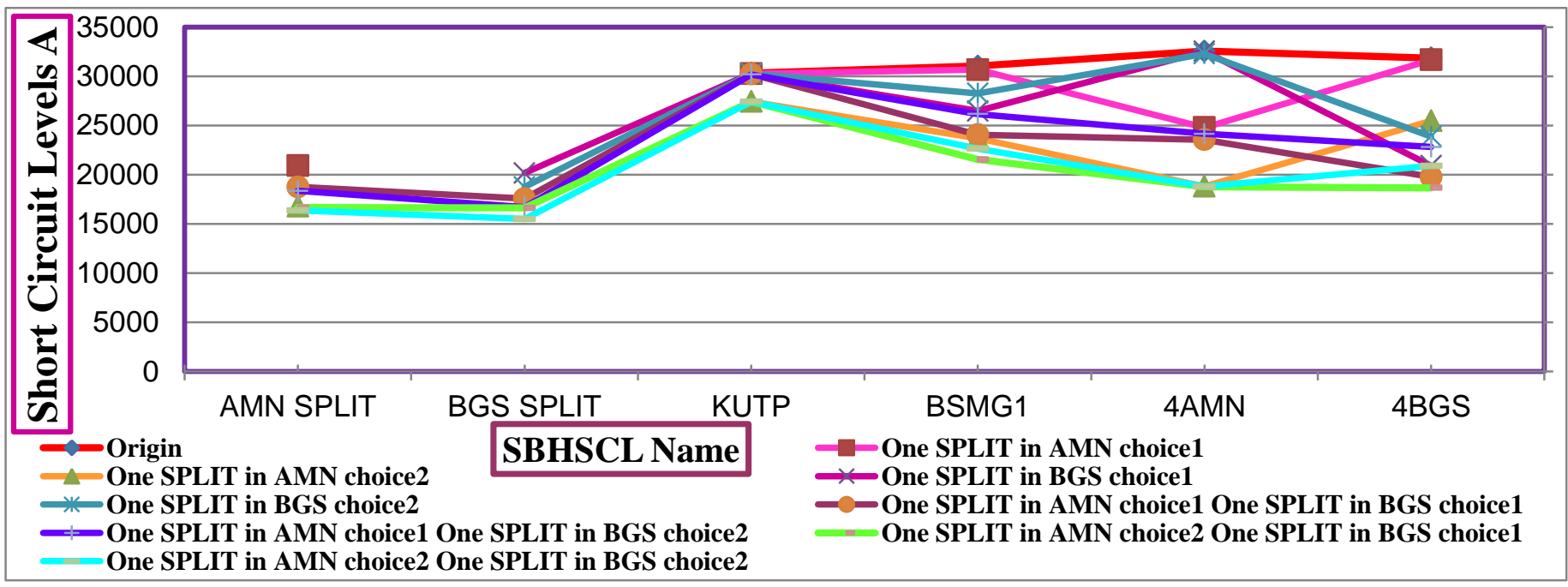

Figure 29:- Three phase short circuit levels for station buses at $400 \mathrm{KV}$ side with splitting choices

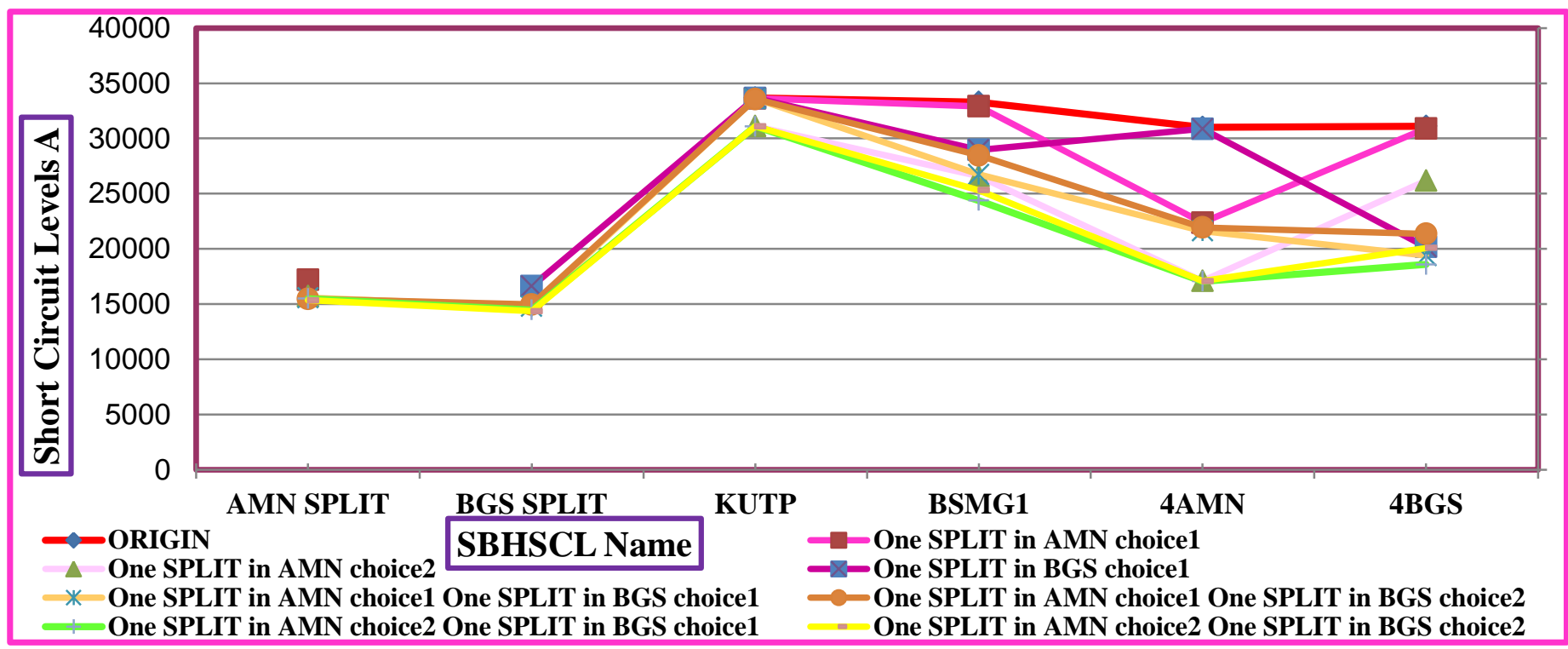

Figure 30: - Single phase short circuit levels for station buses at $400 \mathrm{KV}$ side with splitting choices.

8. Choose the optimal choice which have the lowest values of short circuit levels and the minimum times of splitting for SBHSCL and other substation in the system as follows: -

From Figure (29) the optimal choice for all cases is (one splitting in Al-Ameen substation choice 2 and one splitting in Baghdad south power station choice 1), which reduce the short circuit levels in Al-Ameen substation from $\underline{(32576.5 \angle-86.07)}$ at origin case to $\underline{(\mathbf{1 8 7 8 4 . 3} \angle-85.42)}$ and for Baghdad south from $\underline{(31862.2 \angle-86.11)}$ at origin case to $\underline{\mathbf{1 8 6 7 8 . 5} \angle \mathbf{8 5 . 9 5})}$. Furthermore, the optimal choice for one splitting casa only is (one splitting in AlAmeen substation choice 2) which reduce the short circuit levels in Al-Ameen substation from $\underline{(32576.5 \angle-86.07)}$ 


\section{AL-QADISIYAH JOURNAL FOR ENGINEERING SCIENCES}

Vol. 11 , No. 3

ISSN: $1998-4456$

at origin case to $\underline{\mathbf{( 1 8 8 2 2 . 1 \angle - 8 5 . 4 1 )}}$ and for Baghdad south from $\underline{\mathbf{3 1 8 6 2 . 2 \angle - 8 6 . 1 1})}$ at origin case to (25494.4 $\angle-86.44)$.

From Figure (30) the optimal choice for all cases is (one splitting in Al-Ameen substation choice 2 and one splitting in Baghdad south power station choice1) which reduced the short circuit levels in Al-Ameen substation from $\underline{(31019.3 \angle-83.9)}$ at origin case to $\underline{(17077.4 \angle-82.84)}$ and for Baghdad south from $\underline{(31108.5 \angle-84.27)}$ at origin case to $(\mathbf{1 8 6 0 0 < - 8 4 . 8 3 )}$. Furthermore, the optimal choice for one splitting casa only is (one splitting in AlAmeen substation choice 2) which reduce the short circuit levels in Al-Ameen substation from $\quad \underline{(32576.5 \angle-}$ $\underline{\mathbf{8 6 . 0 7})}$ at origin case to $\underline{(\mathbf{1 7 0 9 8 . 2} \angle \mathbf{8 2 . 8 3})}$ and for Baghdad south from $\underline{(31862.2 \angle-86.11)}$ at origin case to $\underline{(26171.6 \angle-85.01)}$.

\section{CONCLUTION}

From the details mentioned the schedules and curves conclude that the minimizing of substation bus bar short circuit levels is not depending on the number of splitting bus bar but on when and where we will choose the splitting position. The optimum splitting choice with one split place in the overall grid network which may have the minimum difference compared with two splitting places or more. High robustness by minimizing the number of splitting position in the grid. At the same time, the splitting choices are usable for reducing short circuit levels in single phase faults and three phase faults, known that the occurrence of three phase faults is about $5 \%$ but the design of substation depends on the three phase faults or balanced faults. Sometimes the single phase faults maximize the three phase fault when using one of the limitations for the short circuit levels depend on balanced faults. In the current method, the two types of faults reduced.

\section{ACKNOWLEDGEMENTS}

The authors really appreciate ministry of electricity of Iraq offices and company which are Operatinal and Control office and Planing and Development office represented by their general directorate persons and their specialist staff for thier financial support. At the same time appreciate the general directorate persons for Training and Power Researches Office, General Company of Middle Euphrates Transportation and Inspector General Office of MOE for thier specialist staff of thier supports.

\section{REFERENCES}

1. T. Roininen, C. E. Solver, H. Nordli, A. Bosma, P. Jons- son and A. Alfredsson, “ABB Live Tank Circuit Breakers, Application Guide." Publication 1HSM 9543 23-02en, Edition 1.2, 02- 2013.

2. Heresh Seyedi and Barzan Tabei,"Appropriate Placement of Fault Current Limiting Reactors in Different HV Substation Arrangements ", Faculty of Electrical and Computer Engineering, University of Tabriz, Tabriz, Iran. Accepted May 14, 2012 Published Online July 2012.

3. S. Pahwa, M. Youssef, P. Schumm, C. Scoglio, N. Schulz," Optimal intentional Islanding to Enhance the Robustness of Power Grid Networks", Physical, A: Statistical (2013) Mechanics and its Applications, 392(17), 3741-3754.Copyright: (C) 2013 Elsevier B.V. Digital Object Identifier (DOI): doi: 10.1016/j.physa.2013.03.029.

4. Kai Sun, Da-Zhong Zheng and Qiang Lu, "Splitting Strategies for Islanding Operation of Large-Scale Power Systems Using OBDD-Based Methods". Vol. 18, NO. 2, May 2003. 


\section{AL-QADISIYAH JOURNAL FOR ENGINEERING SCIENCES}

Vol. 11 , No. 3

ISSN: $1998-4456$

5. Guangyue $\mathrm{Xu}$ and Vijay Vittal, "Slow coherency based cutset determination algorithm for large power systems". Vol. 25, No. 2, May 2010.

6. David H.Meyer, Thomas Rusnov and Alison Silverstein, "Final Report on the August14,2003 Blackout in the United States and Canada: Causes and Recommendations" U. S. -Canada Power System Outage Task Force, April 5 $5^{\text {th }}, 2004$.

7. Pablo Fernández Porras, Jairo Quirós Tortós."Controlled Islanding with Special Consideration of Parallel Power System Restoration Constraints". Electric Power \& Energy Research Laboratory. School of Electrical Engineering, University of Costa Rica, San Jose, Costa Rica. Ingeniería 27 (1): 113-131, ISSN: 2215-2652; 2017.

8. P. A. Trodden, W. A. Bukhsh, A. Grothey, and K. I. M. McKinnon, "Optimization-based Islanding of Power Networks using Piecewise Linear AC Power Flow", IEEE TRANSACTIONS ON POWER SYSTEMS,Vol.29, No. 3,MAY 201425 October 2013.

9. C. W. Taylor and D. C. Erickson. "Recording and analyzing the July 2 cascading outage [Western USA power system]". IEEE Computer Application Power, vol. 10, pp. 26-30, Jan. 1997.

10. Qianchuan Zhao, Kai Sun, Da-Zhong Zheng, Jin Ma and Qiang Lu, "A Study of System Splitting Strategies for Island Operation of Power System: A Two-Phase Method Based on OBDDs", IEEE Transactions on power systems, VOL.18, No.4, November 2003.

11. J. H. Chow. "Time-Scale Modeling of Dynamic Network with Applications to Power Systems". New York: Springer-Verlag, 1982, Vol. 46, Lecture Notes in Control and Information Sciences.

12. H. You, V. Vittal, and $X$. Wang, "Slow coherency-based islanding". IEEE Transactions on Power Systems, Vol. 19, no. 1, pp. 483-491,2004.

13. R.Baldick, B. Chowdhury, I. Dobson, D. Zhaoyang and G. Bei, D. Hawkins, "Initial review of methods for cascading failure analysis in electric power Meeting, Pittsburgh, PA, USA, Jul, 2008.

14. M. M. Adibi, R. J. Kafka, Sandeep Maram and Lamine M. Mili, "On Power System Controlled Separation", IEEE Transaction on power systems, VOL. 21, NO. 4, NOVEMBER 2006.

15. P. A. Trodden, W. A. Bukhsh, A. Grothey and K. I. M.McKinnon, " MILP formulation for controlled islanding of power networks. International Journal of Electrical Power and Energy Systems ", School of Mathematics, University of Edinburgh James Clerk Maxwell Building, Edinburgh EH9 3JZ, Scotland. (2013), 45 (1). 501 - 508. ISSN 0142-0615, (2013).

16. A. J. Phillips, J. M. Senior, R. Mercinelli, M. Valvo, P. J. Vetter, C. M. Martin, M. O. van Deventer, P. Vaes, and X. Z. Qiu, "Redundancy Strategies for a High Splitting Optically Amplified Passive Optical Network.", JOURNAL OF LIGHTWAVE. TECHNOLOGY, Vol.19, NO.2, February 2001.

17. Kai Sun, " Prevention and Mitigation of Cascading Outages in Power Grids Using Synchrophasor-based Wide-Area Measurements", Stanford University. Electric Power Research Institute, Inc, 8May, 2012.

18. J. B. V. Subrahmanyam and C. Radhakrishna, "Distributed Generator Placement and Sizing in Unbalanced Radial Distribution System". World Academy of Science,Engineering and Technology International Journal of Electrical and Computer Engineering Vol:3, No:4, 2009. 